\title{
Los gobernadores de plazas y la construcción de lugares de poder imperial en los Países Bajos españoles en la época de Felipe II y de los Archiduques
}

City governors and the development of imperial power places in the Spanish Low Countries during the age of Philip the 2nd and the Archdukes

\author{
Yves Junot ${ }^{1}$ \\ Université Valenciennes, Francia \\ José Javier Ruiz Ibáñez² \\ Universidad de Murcia, España
}

\begin{abstract}
Resumen: El texto explora la construcción de lugares de poder regio a través los gobernadores de plazas en los Países Bajos españoles en la época de Felipe II y de los Archiduques. La Monarquía Hispánica logró crear un mecanismo complejo de gestión política de sus plazas confiándolas a oficiales españoles como a nobles locales, ambos eficaces para garantizar una dominación que movilizara apoyo social y la lealtad al lejano rey. Los españoles supieron adaptarse al mundo político local y los naturales no flaquearon en su fidelidad a los Habsburgo. Entre ellos sí comenzaba a crearse una cultura de servicio y de gobierno directo de un soberano ausente; una vía a la promoción que se adaptaba a las realidades de patronazgo y clientela y a la capacidad de representación del territorio pero que primaba la capacidad de integración y de comprensión de la cultura política municipal.
\end{abstract}

Palabras clave: Gobernadores de plazas; monarquía Hispánica; Países Bajos españoles; poder regio; poderes locales; nobleza; ejército; servicio

Abstract: The text explores the construction of places of royal power through the governors of towns in the Spanish Low Countries at the time of Philip II and the Archdukes. The Hispanic Monarchy managed to create a complex mechanism of political management of its towns entrusting them to Spanish officials as local nobles,

\footnotetext{
1 http:// orcid 0000-0003-1967-6716

2 http://orcit 0000-0001-6539-7617. Para José J. Ruiz Ibáñez este artículo se ha realizado en el marco del proyecto "Hispanofilia III: la influencia ibérica en su contexto político, siglos XVIXX", Código: HAR2014-52414-C2-1-P, Ministerio de Economía y Competitividad
} 
both effective to guarantee a domination that mobilized social support and loyalty to a distant king. The Spaniards knew how to adapt to the local political world and the natives did not falter in their fidelity to the Habsburgs. Among them, a culture of service and direct government of an absent sovereign began to be created; a way to the promotion that was adapted to the realities of patronage and clientele and to the capacity of representation of the territory but that prioritized the capacity of integration and understanding of the municipal political culture.

Key words: Governors of towns; Hispanic Monarchy; Spanish Low Countries; royal power; local powers; nobility; army; service

\section{Los centinelas del rey}

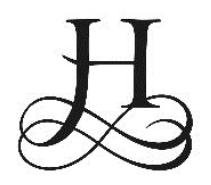

ugo de Schepper en sus trabajos muestra como el poder soberano se construyó a partir de un ejercicio complejo en el que la gracia y la justicia se combinaban para generar expectativas y adhesiones hacia la capacidad redistributiva y punitiva del soberano. ${ }^{3}$ Este binomio en sus potencialidades, en sus frustraciones y en sus límites efectivos resultó básico para estabilizar el poder Habsburgo y para fragilizarlo hasta conducir a la rebelión y a la fragmentación del poder regio en la década de 1560. La administración que se reconstruyó a partir de 1580 también se apoyaría en él, corrigendo errores e integrando en la administración real a nuevos agentes y reforzando los lazos entre el poder central, las realidades políticas locales y los súbditos. En los procesos complejos de construcción efectiva de la autoridad regia la mediación política de múltiples agentes en diversos espacios resultaba decisiva para mantener abiertas las vías de comunicación y para alimentar una lealtad recíproca que se desarrollaba siempre de forma conflictiva. Por ello estudiar a los agentes del poder soberano más próximos a las realidades municipales en Flandes parece oportuno, dado que sí las burguesías católicas y la corte habían estado de acuerdo en establecer el régimen monárquico, tal pacto, que resultaría decisivo para su supervivencia en la década de $1590,{ }^{4}$ debía de ser interpretado en lo cotidiano.

\footnotetext{
3 Hugo De Schepper, "Justicia, gracia y policía en Flandes bajo el Duque de Alba (1567-1573)", en V Centenario del Nacimiento del III Duque de Alba, Fernando Alvarez de Toledo. Actas: Piedrahíta, El Barco de Ávila y Alba de Tormes (22 a 26 de octubre de 2007), (Ávila, Diputación de Ávila, Institución Gran Duque de Alba: Diputación de Salamanca, 2008), pp. 461-471 y "Pena o gracia en Flandes bajo Carlos V y Felipe II (1521-1598)", en Felipe II (1527-1598): Europa y la monarquía católica, comp. José Martínez Millán, (Madrid: Parteluz, 1998), Vol. 1, Tomo 2, pp. 795-814.

${ }^{4}$ La movilización de las milicias de algunas de estas villas que contaban con gobernador resultó decisiva para contener las ofensivas francesas y holandesas a partir de 1594, una visión general en José Javier Ruiz Ibáñez, "Se mobiliser pour le roi à la fin du XVI ${ }^{\mathrm{e}}$ siècle dans les villes des Pays-Bas catholiques", en Les milices dans la première modernité, comp. Serge Brunet y José Javier Ruiz Ibáñez, (Rennes: Presses Universitaires de Rennes, 2015), pp. 155168. Es importante recordar que a la hora de movilizar a las milicias contra las sorpresas de
} 
Entre los conocidos informes que preparó en 1596 el siempre ácido secretario de Estado y Guerra en Bruselas, Esteban de Ibarra5, mientras esperaba en la ciudad de Calais embarcarse para España, se encuentra un significativo recuento de los gobernadores de plazas, 0 , al menos de aquéllas que eran los suficientemente significativa como para que Ibarra reseñara su importancia y caracterizara a los hombres del rey. Eran poblaciones disímiles en las que la presencia efectiva de poder imperial variaba enormemente, pero que no resultaban indiferentes al esquema de dominación de los Habsburgo en los Países Bajos, ni política, ni militarmente. En algunas, como Arras en Artois, el rey católico ni siquiera tenía guarnición, en otras como la ocupada en 1595 Doullens en Picardía (Francia), la presencia de las tropas reales era abrumadora. No hay una descripción de la diversidad de situaciones políticoadministrativas o jurídicas de estas villas, sino de las características personales de cada gobernador y de su eficacia como tal, dado que el secretario los juzga como pieza clave de la gestión del poder soberano. Con sus críticas, y también con su reconocimiento de méritos, Ibarra define en positivo y negativo el ideal tipo que corresponde a un gobernador. Con todo, para él, y contra la realidad de lo que estaba afirmando, lo ideal hubiera sido colocar en las plazas sensibles a españoles naturales o al menos a criaturas del rey cuya carrera dependiera de su favor. Pero más allá del hispanocentrismo del sulfuroso secretario, que no hay que olvidar que detestaba de forma indisimulada a la nobleza autóctona, se puede encontrar las principales cualidades que para él definen a un buen agente del rey católico y los principales defectos que para él adornaban a quienes en la práctica ejercían tales cargos.

Ahora bien, más allá de sus filias y fobias personales, de su competencia o inutilidad, la constatación de Ibarra sobre la fidelidad de estos hombres del rey es muy significativa respecto al tipo de administración que estaban construyendo, y que estaba construyendo, los Países Bajos católicos.

En un informe escrito en las mismas fechas y con el mismo fin de presentar a la administración real en su componente humano, el secretario describía a la alta nobleza, esa entre la que se reclutaban los miembros del Consejo de Estado o los gobernadores provinciales como un grupo sólo a medias fiable, con abiertos antecedentes de deslealtad al rey y, desde luego, muy amante de la defensa de sus intereses. No era así, no lo era al menos en una parte considerable, en lo que se refiere a los gobernadores de plazas. El secretario los definía como muy mayoritariamente leales y, con todas las tonalidades posibles, bien dedicados al servicio regio. Esto se daba por sobreentendido

los enemigos del rey tanto los gobernadores naturales (Saint-Omer en 1594 o Arras en 1597) como los foráneos (Amberes 1595) resultaron eficaces, lo que viene a corroborar la idea de la existencia de un carácter y una formación común.

${ }^{5}$ Sobre el secretario y su gestión en los Países Bajos se remite a José Eloy Hortal Muñoz, EI manejo de los asuntos de Flandes, 1585-1598, (tesis doctoral, UAM, 2004) pp. 178-276: en la nota 73 de esta última página se registra el listado de informes elaborados por el secretario, parte de los cuales se conservan en el Archivo General de Simancas (en adelante AGS). 
para los españoles (de origen familiar o nacimiento) y para otros extranjeros súbditos naturales del rey, pero también era una cualidad que se reconocía a los gobernadores autóctonos: de los casi veinte que identificaba Ibarra sólo dos habían levantado armas contra el soberano en los tiempos de los tumultos. ${ }^{6}$

Se definía así una múltiple sociología política que puede ayudar mucho a comprender las bases de la solidez del régimen monárquico que se estaba asentado en Flandes después de los éxitos del gobernador general de los Países Bajos Alejandro Farnesio, duque de Parma, en la década de $1580 .{ }^{7} \mathrm{La}$ Monarquía parecía haber tenido que pactar con los grandes nobles descontentos, muchos de los cuales efectivamente habían sido indiferentes o rebeldes al rey y también con los gobiernos locales. Cierto, esa gran nobleza había sido muy importante a la hora de refundar los consensos políticos y activar a sus clientelas; pero parece claro que no bastaba. Cada día se tiene más claro que el éxito político de Parma se basó esencialmente en lograr un acuerdo con parte de la nobleza, los líderes municipales y las burguesías católicas que reaccionaban contra una revuelta que ya no identificaban como su suya. ${ }^{8}$ Pero entre esas burguesías, la corte de Bruselas y el soberano surgían para lograr el asentamiento del nuevo régimen unas importantes figuras mediadoras fundamentales en un entramado político que cada vez se hacía más y más complejo. ${ }^{9}$ Curiosamente sabemos más sobre los obispos, el retorno y la llegada de las nuevas órdenes (jesuitas, carmelitas descalzos) o la fundación de establecimientos de refugiados que sobre los agentes

\footnotetext{
${ }^{6}$ AGS, Estado (en adelante E) 612, n' 114 y 116, 25 de marzo de 1596, Bruselas, Las personas que están por gobernadores de las plaças fuertes de las fronteras y otros presidios destos Estados.

7 Sobre el desarrollo político, cultural y religioso de la revuelta de los Países Bajos y del restablecimiento posterior contamos con algunas visiones recientes: Alain Lottin y Philippe Guignet, Histoire des Provinces françaises du Nord. De Charles Quint à la Révolution française (1500-1789), (Arras: Presses Universitaires, 2006); Catherine Denys y Isabelle Paresys, Les anciens Pays-Bas à l'époque moderne (1404-1815). Belgique, France du Nord Pays-Bas, (París: Ellipses, 2007); Judith Pollmann, Catholic Identity and the Revolt of the Netherlands, 1520-1635 (Oxford-New York: Oxford University Press, 2011); Geert H. Janssen, The Dutch Revolt and Catholic Exile in Reformation Europe (Cambridge: Cambridge University Press, 2014).

${ }^{8}$ Sobre la restauración del régimen Habsburgo en los Países Bajos hay un creciente interés que supera la visión de una simple conquista militar y hace hincapié en unos procesos de negociación que no eran completamente originales; se remite a Violet Soen, "Reconquista and Reconciliation in the Dutch Revolt. The campaign of Governor-General Alexander Farnese in the Dutch Revolt (1578-1592)", Journal of Early Modern History 16, (2012), pp. 1-22; Thierry Wanegffelen, "Entre concorde et intolérance; Alexandre Farnèse et la pacification des PaysBas," en De Michel de l'Hospital à l'édit de Nantes. Politique et religion face aux Églises, ed. Thierry Wanegffelen (Aubenas d'Ardèche: Presses Universitaires Blaise Pascal, 2002), pp. 5170; Yves Junot, "Pratiques et limites de la réconciliation après les guerres de religion dans les villes des Pays-Bas méridionaux (années 1570-années 1590)", Revue du Nord, 395-2, (2012), pp. 327-346 ; José Javier Ruiz Ibáñez, "La integración de los Países Bajos en la Monarquía Hispánica," en Las Indias Occidentales. Procesos de incorporación territorial a las Monarquías Ibéricas, comp. Óscar Mazín Gómez y José Javier Ruiz Ibáñez, (México: El Colegio de México, 2012), pp. 109-152.

9 Hugo De Schepper, "El funcionariado y la burocratización en el gobierno y en las provincias de Flandes Regio, siglos XVI y XVII," en Chronica nova: Revista de historia moderna de la Universidad de Granada 23, (1996), pp. 403-436.
} 
propiamente administrativos encargados de desarrollar la negociación cotidiana con esas elites locales.

Las biografías políticas de los protagonistas del primer informe de Ibarra muestran como la Monarquía pudo disponer de un grupo sólido de nobles de mayor o menor alcurnia y de soldados que en parte se habían hecho a sí mismos entre los que reclutar sus agentes de confianza. La imagen puede ser leída de forma inversa. Un grupo de la media y baja nobleza había apostado desde hacía al menos dos o tres décadas firmemente por aliarse con la corona y ahora ésta podía reclutar entre estos servidores fiables a sus hombres de confianza; pero también se ponía de manifiesto como la dominación imperial de la Monarquía había traído cambios y ahora se sostenía sobre una administración política en la que los agentes sobre el territorio incluían no sólo a los hombres del lugar, sino a otros que hallaban en la gestión misma del poder monárquico una forma de promoción social y en la circulación en el servicio la vía para desarrollarlo. Ambos elementos, localidad y proyección imperial, quedan en el caso de los gobernadores así al descubierto mostrando a la Monarquía como algo más que un agregado de territorios, sino un compuesto complejo y vital dependiente de coyunturas específicas y de tendencias genéricas.

Por lo que respectaba a los nativos lo que se verificaba para finales del siglo XVI no era particularmente diferente de lo que se había dado y se estaba dando en los territorios vecinos. La simbiosis entre el poder del príncipe y la presencia de una nobleza segunda firmemente asentada en el territorio o integrada en el servicio regio se había mostrado muy eficaz para la consolidación del poder regio en las vecinas Picardía y Champaña una vez expulsados los borgoñones a finales del siglo $X V,{ }^{10}$ o en las fronteras de la Monarquía francesa con Lorena durante la guerra civil ya en la centuria siguiente. ${ }^{11}$ Este grupo social, que llegó a expresarse en las Ligas nobiliarias

\footnotetext{
10 Tras la conquista, la especialización de una serie de familias de mediana nobleza local en el servicio de las armas y en el gobierno de plazas reforzó su dependencia con la Monarquía francesa al tiempo que garantizó una amplia continuidad política en la gestión efectiva del poder del rey Cristianísimo en el valle del Soma, un zócalo sobre el que se iba a asentar la propia Monarquía francesa por más de un siglo; David Potter, War and Government in the French Provinces: Picardy, 1470-1560 (Cambridge: Cambridge University Press, 1993); Laurent Bourquin, Noblesse seconde et pouvoir en Champagne, auX XVI ${ }^{e}$ et XVII siècles (París: Publications de la Sorbonne, 1995). Sobre este grupo social recordar los trabajos de Jean-Marie Constant, "Un groupe socio-politique stratégique dans la France de la première moitié du XVII siècle: la noblesse seconde", en L'État et les aristocraties (France, Angleterre, Écosse), XII ${ }^{-}-X V I I^{e}$ siècle, comp. Philippe Contamine (París: Rue d'Ulm, 1989), pp. 279-304; Brian Sandberg, Warrior Pursuits: Noble Culture and Civil Conflict in Early Modern France, (Baltimore: The Johns Hopkins University Press, 2010). Laurent Bourquin, Les nobles, la ville et le roi: I'autorité nobiliaire en Anjou pendant les guerres de religion (1560-1598), (París: Belin, 2001). Los trabajos de Stuart Carroll permiten comprender las formas de construcción de las clientelas nobiliarias en la vecina Picardía y el papel jugado en ellas por una nobleza segunda que habría de vascular entre el servicio al rey y la adhesión a las grandes casas: Noble Power during the French Wars of Religion. The Guise Affinity and the Catholic Cause in Normandy, (Cambridge: Cambridge University Press, 1998) y Blood and Violence in Early Modern France, (Oxford: Oxford University Press, 2006).

${ }^{11}$ Martial Gantelet, L'absolutisme au miroir de la guerre. Le roi et Metz (1552-1661) (Rennes: Presses Universitaires de Rennes, 2012), pp. 67-109.
} 
de las décadas de 1560-1600, logró resistir a los cambios en la gubernatura de las Provincias y terminó por ser decisivo a la hora de pactar su pacificación después de 1593, pues habían sido ellos, los gobernadores de plazas quienes, en ocasiones a despecho de los gobernadores provinciales, habían terminado por hacer bascular las provincias hacia Enrique IV. ${ }^{12}$

La autonomía de la nobleza segunda había nacido de su propia residencia sobre el territorio, en la que tenían no pocas propiedades y relaciones, y de su capacidad de movilizar hombres, y en gran parte se había consolidado en su relación con el duque borgoñón una vez superada la prueba que significó los desencuentros entre nobleza y príncipe en la época de Carlos el Temerario ${ }^{13}$ y la invasión francesa. En las guerras subsiguientes las lealtades habían salido reforzadas sobre todo por la mayor presencia de los recursos militares imperiales tras la década de 1530. Sería dentro de esa nobleza segunda católica, que se veía como borgoñona por oposición a los franceses y que conocía bien la guerra de frontera, que se reclutaría una parte sustancial de los gobernadores.

Los otros agentes, los foráneos, tampoco en extraños en los diversos territorios de la Monarquía. Su propia presencia evoca la irrupción de nuevas formas de poder soberano y de una capacidad de superposición a las tradiciones y jurisdicciones locales que podía nacer del simple ejercicio de la fuerza, vía conquista o represión de plazas, o de la concentración de recursos, dado que un cargo nuevo pagado por la tesorería personal del príncipe podía escapar a las normas de control jurisdiccional de las instituciones regnícolas o municipales. Si en cierto sentido, y con todas las reservas, los encomenderos podían jugar ese papel en América, en territorios que habían pasado a la jurisdicción imperial vía conquista, ex nihilo o con pretensión de liberación-restauración, ${ }^{14}$ el príncipe se podía sentir en el derecho de repartir entre 'sus' hombres cargos que implicaran el control tradicional del territorio o su nueva organización. Caso particularmente significativo es el de los capitanes españoles a través de los que organizó el territorio de L'Aquila una vez que este fue sometido tras la revuelta antiespañola que acompañó a la campaña de Lautrec en Nápoles. ${ }^{15}$ El que parte de estos oficiales fueran peninsulares no debe invitar a una visión clásica de una 'dominación

\footnotetext{
12 Nicolas Le Roux, La faveur du roi: mignons et courtisans au temps des derniers Valois, (Seyssel: Champ Vallon, 2000), pp. 556-558.

${ }^{13}$ Élodie Lecuppre-Desjardin, Le royaume inachevé des ducs de Bourgogne : XIVE-XVe siècles, (París: Belin, 2016), cap. III.

14 El tipo de disponibilidad de oficios por la administración directa del soberano y de sus órganos de gobierno dependía en gran parte de la forma de integración imperial de cada uno de los territorios y del nivel efectivo de pacto a través del cual se desarrollaba, en los últimos años hay una amplia bibliografía sobre los mecanismos de agregación que se integra en parte en el debate de la construcción territorial de la Monarquía; una visión de conjunto en Xavier Gil Pujol, La fábrica de la Monarquia. Traza y conservación de la Monarquía de España de los Reyes católicos y de los Austrias (Madrid: Real Academia de la Historia, 2016) cap. 2.

15 Gaetano Sabatini, "Le sentinelle della corona. Capitani spagnoli ai confini settentrionali del regno di Napoli nel Cinquecento," en La Espada y la pluma: il mondo militare nella Lombardia spagnola cinquecentesca, comp. Mario Rizzo (Lucca: Baroni, 2000), pp. 55-84.
} 
hispánica', sino que parece más sugerente usarlo para reflexión la coyuntura de una Monarquía que habría de resultar muy maleable con el tiempo. No hay que olvidar que esto se relaciona con un momento, el de máxima hispanización de la Monarquía. Este hecho no debe ocultar que antes que nada los gobernadores eran hombres del rey, ${ }^{16}$ lo que anunciaba una presencia cada vez mayor del poder soberano sobre el territorio, ${ }^{17}$ un poder soberano que recurría a personas formadas en su administración directa que podían resultarle de confianza y que hacían carreras que en muchos casos se desarrollaban en los múltiples espacios de la Monarquía. ${ }^{18}$ Salvando las distancias, y son muchas, el carácter extraño de estos extranjeros con los poderes locales no estaba tan lejos del que pudieran tener los corregidores castellanos de capa y espada respecto a las ciudades que les tocaba gobernar. Pero si unos y otros, naturales y extranjeros, eran gobernadores hay que aclarar primero sus funciones y sus poderes.

\section{Funciones, tipos, autoridad}

En el largo conflicto que enfrentó a los soberanos con las villas que reconocían su autoridad, la presencia física de los hombres del príncipe fue siempre una anomalía. Si la ciudad era leal y si, en el fondo, era esa fidelidad la que sustentaba la dominación, parecía que el acuerdo entre burguesía y señor debía bastar. Sin embargo, en la Baja Edad Media la lejana autoridad regia se va haciendo acompañar cada vez más de una presencia física, bien como resultado del incremento del poder del príncipe, bien como su irrupción en tanto que mediador de los diversos conflictos sociales y políticos que cuartean a las villas. Los gobernadores municipales fueron consolidando en el espacio urbano norte-europeo como un medio de afirmar la autoridad regia y de buscar consolidar su poder, ${ }^{19}$ por supuesto los medios con que pudiera

\footnotetext{
16 Juan Francisco Pardo Molero y Manuel Lomas Cortés, "Introducción" en Oficiales reales los ministros de la Monarquía Católica, siglos XVI-XVII (Valencia: Universitat de València, 2012), pp. 9-22; Alicia Esteban Estríngana, "El servicio: paradigma de relación política en los siglos XVI y XVII," en Servir al rey en la Monarquía de los Austrias. Medios, fines y logros del servicio al soberano en los siglos XVI y XVII (Madrid, Sílex: 2012) pp. 11-45.

17 No hay que olvidar que estas tendencias, la hispanización y el incremento del poder regio, en parte se contendrían o incluso se invertirían a lo largo del siglo XVII. Sin querer entrar aquí en ese debate, si es reseñar que la Monarquía tuvo incluso dificultad para determinar cuántos cargos tenía disponibles, dado que muchos de ellos iban a ser designados por sus delegados territoriales, aunque los beneficiarios estuvieran en movimiento. En ese sentido resultan muy interesantes los intentos por conocer al menor en el, en teoría, más homogéneo espacio americano los oficios que estaban disponibles para ser otorgados por el rey; Guillaume Gaudin, Penser et gouverner le Nouveau Monde au XVII siècle. L'empire de papier de Juan Díez de la Calle, commis du Conseil des Indes (París: L'Harmattan, 2013).

18 La circulación de los agentes militares dentro de la Monarquía Hispánica ha atraído la atención de la historiografía en los últimos años, para lo que se remite a Domingo Centenero de Arce, "¿Una monarquía de lazos débiles? Circulación y experiencia como formas de construcción de la Monarquía Católica" en Oficiales reales los ministros de la Monarquía Católica, siglos XVI-XVII (Valencia: Universitat de València, 2012), pp. 9-22.

19 Hugo De Schepper, "Centralismo y autonomismo en los Países Bajos durante el siglo XVI," en Centralismo y autonomismo en los siglos XVI-XVII: homenaje al profesor Jesús Lalinde
} 
contar cada uno facilitaban o entorpecían su tarea, y no solo se trataba de hombres armados.

La presencia del gobernador complicaba aún más las jurisdicciones dentro de los muros, dado que él y sus hombres representaban al príncipe en el conjunto del casco urbano y no sólo en los espacios que de iure le correspondían tales como, caso de haberlo, el castillo señorial o la simple residencia. Integrante de la comunidad y ajeno a ella de forma radical, el gobernador estaba tan lejos de ser un agente directo y burocrático del soberano que pudiera imponer su voluntad en una sociedad que le era completamente extraña y como de un representante de la población. Su carácter de nobleza, y una nobleza confirmada o ganada con el ejercicio de las armas, si establecía una separación con la corporación urbana, a su cultura política y a sus tradiciones, pero al mismo tiempo el gobernador debía guiar y proteger, frente al enemigo exterior y frente a la administración central misma, a 'su' ciudad, defender la dignidad de su cargo y buscar su interés generando una ambivalencia efectiva en su ejercicio. ${ }^{20}$ Por el bien de la dominación regia y por la consecución de los propios intereses, el gobierno era en primer lugar un ejercicio de traducción de culturas políticas diversas, un ámbito de negociación, acción política y gestión militar en la que su ocupante debía ser consciente de la coyuntura y de las diversas fuerzas e intereses en competición.

\section{1) El ejercicio del poder regio en la jurisdicción municipal y en zona fronteriza}

Aunque el informe de Ibarra se concentra en la posición de las autoridades de las plazas estratégicamente significativas, la presencia de estos agentes regios se ampliaba a la mayor parte de las localidades. La función básica de un gobernador era ejercer el poder regio en la jurisdicción municipal y, a diferencia de lo que pasaba en otros territorios, no había una uniformidad de sus atribuciones. Aunque muchas de las afirmaciones de Jerónimo Castillo de Bobadilla en su famosa, y casi estrictamente contemporánea a los informes de Ibarra, Política para Corregidores y Señores de Vasallos, en tiempo de paz y de guerra podrían aplicarse a los gobernadores de villas de Flandes, la diversidad jurisdiccional era tal que más allá de una serie de elementos comunes cada caso implicaba una realidad bien diferente. Aunque insertos en los Países Bajos, los municipios formaban parte de 'provincias' que contaban con su propia forma de inserción en el conglomerado borgoñón, una atomización que iba más allá si se recuerdan otros dos elementos en la escala

Abadía, comp. Aquilino Iglesia Ferreirós y Sixto Sánchez-Lauro Pérez, (Universitat de Barcelona, 1990), pp. 487-516.

20 Es eficaz usar este término en el sentido que lo usa Robert Merton, de la misma forma que se puede hacer respecto a los corregidores en Castilla o a otros delegados regios de este periodo; José Javier Ruiz Ibáñez, Las dos caras de Jano. Monarquía, ciudad e individuo. Murcia, 1588-1648 (Murcia, Universidad de Murcia, 1995), cap. II.1. 
administrativa, uno ascendente (la existencia de consejos provinciales) y otro descendente (la singularidad jurisdiccional de cada villa) . Como dicho poder había definido sus límites de forma diversa en cada población por los vaivenes políticos de los dos últimos siglos ${ }^{21}$ y más aún de las dos últimas décadas, las atribuciones del gobernador variaban enormemente y también la libertad que tenía el gobierno central para designarlo independientemente de su procedencia.

Sus funciones prácticas no iban a ser nada banales. Como representante regio cumplía un rol eminente en la elección de la magistratura urbana (échevinage), que generalmente se renovaba anualmente. Este papel tendía a reforzarse tras la rebelión de los Países Bajos bajo el reinado de Felipe II. La restauración de la obediencia al monarca significaba la renovación del sistema de presentación del nuevo equipo por las propias elites municipales, en provecho de una selección individual y cuidadosa operada por el gobernador de la plaza en función de méritos personales y de criterios de lealtad y de fe romana. Bien como presidente de la comisión de renovación, junto a un enviado de la corte (con preferencia de uno de los consejos centrales de Bruselas o del consejo provincial correspondiente), como informante de las personas beneméritas que debían ocupar los cargos, el gobernador había tejido unos lazos firmes con la sociedad local, que posiblemente se reforzaban gracias a las acciones propias del delegado regio que participaba de forma destacada en el ritual urbano, en la organización militar cívica ${ }^{22}$ y en el gobierno mismo de la ciudad. ${ }^{23}$

\footnotetext{
${ }^{21}$ La posición de origen respecto al poder del príncipe, y de su representante, de cada villa había sido modulado por el devenir político de la Comuna, de su posición de negociación respecto a los duques de Borgoña y de su pacto con los Habsburgo después de 1478. Múltiples casuísticas hacían que para antes de la revuelta la situación fue de por sí muy compleja y hubiera que gobernar villa a villa, sin olvidar tampoco la presencia de un fuerte discurso republicano con el que eran preciso coexistir; Helmut G. Koenigsberger, Monarchies, States Generals and Parliaments. The Netherlands in the fifteenth and sixteenth centuries (Cambridge: Cambridge University Press, 2001); Lecuppre-Desjardin, Le royaume inachevé, pp. 299-312.

22 Manuel Herrero Sánchez y José Javier Ruiz Ibáñez, "Defender la patria y defender la religión: las milicias urbanas en los Países Bajos españoles, 1580-1700", en Las milicias del rey de España. Sociedad, política e identidad en las Monarquías Ibéricas, comp. José Javier Ruíz Ibáñez (Madrid: Fondo de Cultura Económica, 2009), pp. 270-278; Yves Junot, "Les milices bourgeoises au temps des guerres civiles: force de déstabilisation ou instrument de pacification de la société urbaine? (Valenciennes, Anciens Pays-Bas espagnols, 1560-1600)," en Les milices dans la première modernité, comp. Serge Brunet y José Javier Ruiz Ibáñez, pp. 31-42.

${ }^{23}$ Archives Générales du Royaume de Bruselas (en adelante AGR), Papiers d'Etat et Audience (en adelante PEA) 1804/1, sin número, 8 de abril de 1588, Bruselas, Farnesio a Cristóbal de Mondragón, castellano de Amberes: "comme le temps du renouvellement de la Loy d'Anvers approche et que pour la longue demeure qu'avez faict celle part, il ne peult estre aultrement que n'ayez quelque cognoissance des plus gens de bien zéleux et affectionnez à $n^{\text {re }} s^{\text {te }}$ foy catholicque romaine et $\mathrm{n}^{\text {re }}$ service, à ceste cause pour le désir qu'avons que lad loy puist estre bien pourveue il nous a semblé bon vous faire cestes pour vous requérir et ordonner nous advertir au plus tost de quelques personnaiges en lad ville que jugerez des plus ydoines qualiffiez gens de bien catholicques et affectionnez au service de Dieu et le $\mathrm{n}^{\text {re }}$ pour estre mis en lad loy pour l'année prochaine et d'iceulx dresser ung billet signé de $v^{\text {re }}$ main pour y avoir le regard".
} 
La intervención directa en la consolidación institucional de la elite urbana sobre la que se sostendría el régimen Habsburgo, tenía sus contrapartidas. Ante ella y/o sus corporaciones se presentaría el gobernador para solicitar la conexión de servicios extraordinarios, el pago puntual de los impuestos o para representar la necesidad de socorrer con hombres, milicianos y gastadores a los ejércitos regios. Los gobernadores ejercían en ocasiones la presidencia de los tribunales locales, comandaban las fuerzas profesionales, caso que las hubiera, y tomaban el mando superior sobre las milicias locales par funciones defensivas.

Estos gobernadores tenían una amplia capacidad de intervenir sobre las ciudades y sus entornos dado que podían también dar licencias, pasaportes, salvaguardas, patentes de corso, gestionar ciertos impuestos, negociar neutralidades y actuar como interlocutores de sus poblaciones con el gobierno central a propósito del alojamiento de los soldados y de la fiscalidad. Este último punto es importante, pues estas atribuciones, administrativas y fácticas, iban más allá del mero gobierno local y se proyectaban sobre la relación entre éste y el poder central como mediadores de las peticiones personales y de las expectativas de la elite local. Tal acumulación de funciones y de espacios de acción extraordinaria, que excedía con mucho a las comisiones que podían recibir, se justificaba por asumir que era su responsabilidad la salvaguarda de las villas, lo que les daba un notable espacio de actuación para conseguir los recursos necesarios: tenían que imponerse como beneficiarios de una parte de las aides otorgadas por los Estados provinciales a un rey en carestía crónica de recursos financieros y que retrocedía poco a sus gobernadores locales, así como obtener préstamos o el cobro de tasas por parte de los mercaderes locales y de los échevinages a cambio de la facilitación y de la seguridad del comercio fronterizo. ${ }^{24}$

Conocedores del terreno, estos hombres desarrollaban sus propias políticas regionales y ponían en pie toda una red de contactos y avisos que podía ser de interés para el gobierno central En circunstancias menos formales desarrollaban un sistema de recopilación de información por medio de una red de agentes y espías pagados de su propio dinero, lo que alimentaba su correspondencia con Bruselas y así potenciaban su posición en opinión del gobernador general. El gobernador de la pequeña villa de Landrecies en Hainaut, Charles de Largilla, en relación epistolar con un teniente local del duque de Guisa del otro lado de la frontera, solía informar a Margarita de Parma y al duque de Alba de los movimientos de tropas católicas y hugonotes en la Picardía vecina sino también de todo lo que ocurría en la Corte de Carlos IX entre las facciones aristócratas de los Guisa, Condé

24 Eso resalta también en la correspondencia del gobernador francés de Boulogne: David Potter, Un homme de guerre au temps de la Renaissance. La vie et les lettres d'Oudart du Biez, maréchal de France, gouverneur de Boulogne et de Picardie (vers 1475-1553) (Arras: Artois Presses Université, 2001). Véase también Bram De Ridder, Lawful Limits. Border Management and the Formation of the Habsburg-Dutch Boundary, ca. 1590-1665, (Tesis doctoral, KU Leuven Lovaina, 2016), cap. 2-4. 
y Coligny. ${ }^{25}$ Valentin de Pardieu, señor de la Motte, gobernador de Gravelinas, y su teniente Philippe de Guernonval mantenían una red de contactos secretos ante sus homólogos de Calais y Boulogne (en particular entre los soldados de la guarnición), con el teniente general de Picardía y con la Corte de Isabel I en Londres. ${ }^{26}$ En 1600, el rey eligió a Fernán López de Villanova, desde 1589 gobernador de Carpen en la frontera con el Sacro Imperio, ya empleado en varias comisiones en Dinamarca y en Alemania, como nuevo residente en la Corte de Cristián IV y en las ciudades hanseáticas. López de Villanova tenía que supervisar la regulación del comercio marítimo entre el Báltico, los Países Bajos de los Archiduques y los reinos de España para luchar contra los fraudes de los holandeses. ${ }^{27}$ Esta configuración de hombres de frontera otorgaba a los gobernadores de plaza una función mediadora entre el soberano, sus súbditos y los vecinos de sus dominios. Su lealtad era, por lo tanto, un punto de primera importancia para el poder central y los recientes conflictos en Francia y en los mismos Países Bajos estaban mostrando como la posición de un gobernador podía resultar decisiva a la hora de hacer bascular en uno u otro sentido la lealtad de una villa.

\section{2) Una proyección territorial variable}

Valiéndose de estas funciones, los gobernadores las ejercían en el marco de un espacio jurisdiccional formalmente establecido, pero cuyos límites se redefinían por el efecto de la guerra misma. El mismo título que ejercían era variado dependiendo del contexto político y algunas ciudades de hecho no tenían gobernador estricto sensu aunque sí hubiera una persona que ejerciera como tal. Los cargos podían acumularse dando lugar a figuras de muy significativa proyección territorial, en particular adonde ocurrieron episodios de conquista militar, de ocupación y de incorporación a la Monarquía Hispánica. Desde la incorporación de Cambrai en los Países Bajos españoles en 1595, el gobernador de la villa era al mismo tiempo castellano de la ciudadela, gobernador de la provincia y su capitán general. ${ }^{28}$ Cargos muy parecidos tenía el gobernador de Calais quien ejercía durante el breve dominio español (1596-1598) una teórica superioridad sobre los territorios ocupados por los españoles en Francia, lo que daba lugar a una cierta

\footnotetext{
25 AGR, PEA 1740/1, sin número. En particular 13 de enero de 1574, Landrecies, Largilla al duque de Alba: "j'ay déboursé à l'ordonnance du duc d'Albe pour les espies et advertissemens dois le temps de la surprinse de Valenciennes et Mons, suppliant Vre Ex ${ }^{\text {ce }}$ volloir commander à ceulx des finances de ordonner au recepveur du desmaine du roy en ceste ville me délivrer et rembourser les susd. 235 florins affin que je puisse continuer en ce pour le service de Sa Maté et de $V^{r e}$ Ex ce car il fault journellement avoir la main sur la bourse quy veult entretenir telle manière de gens".

${ }^{26}$ AGR, PEA 1803/4, 30 de agosto de 1590 y 08 de marzo de 1592, Guernonval al conde de Mansfeld.

27 AGS, E 617, n¹00, 26 de octubre de 1600, Bruselas, Baltazar de Zúñiga a Felipe III. Ibarra escribía en el informe de 1596 que el gobernador de Carpen "tiene todas las lenguas".

28 José Javier Ruiz Ibáñez, Felipe II y Cambrai: el consenso del pueblo. La soberanía entre la práctica y la teoría política. Cambrai (1595-1677) (Rosario: Prohistoria, 2003), pp. 112-118.
} 
ambigüedad ante el estatuto de la vecina villa de Ardres, que también contaba con su propio gobernador. ${ }^{29}$

En otros casos, el gobierno político y el militar estaban disociados, sobre todo cuando había una ciudadela regia o una fortaleza menor y su castellano no tenía de iure una función administrativa sobre la ciudad. Dicho de otra forma generalmente los gobernadores eran castellanos, aunque las fortalezas fueran poco relevantes, pero no todos los castellanos llegaban a ser gobernadores de las plazas que señoreaban. Tal vez era un medio para intentar moderar la fuerte presencia que de por sí ya ejercían sus ciudadelas y una forma de reafirmar la perennidad de los derechos de las burguesías locales, pero los castellanos de Amberes y Gante, posiblemente los más significativos de Flandes, no sumaban a su título el de gobernador, y eso tampoco reducía dramáticamente su capacidad de intervención. ${ }^{30} \mathrm{El}$ castellano de Amberes ejercía desde 1585 la supervisión del rio Escalda más allá de la ciudad, es decir de la nueva frontera y de sus fuertes que controlaban el tráfico de los barcos y el tránsito de personas hacia o desde las Provincias Unidas. ${ }^{31}$

Estas competencias territoriales fuera de los muros de las villas entretenían constantemente rivalidades y tensiones con otros oficiales del rey en la apropiación de los recursos sacados del comercio transfronterizo y marítimo. Los castellanos de Amberes protegieron, en repetidas ocasiones, sus derechos de los superintendentes de los fuertes de la Escalda (donde se recaudaban los impuestos sobre los navíos) contra las interferencias del Consejo de Finanzas y de los oficiales de las licencias, y el gobernador de Gravelinas Guernonval actuó ante el secretario Ibarra para obtener el 10\% de las capturas en mar en lugar del Almirantazgo. ${ }^{32} \mathrm{Al}$ considerar que sus distritos estaban en zona de guerra, estos oficiales asumían que tales derechos les correspondían para financiar la defensa, lo que ampliaba sus competencias no sólo a los dominios de su señor, sino a las zonas de influencia que éstos pudieran tener sobre territorios enemigos y a los particulares e instituciones que se vieran afectados en dichos procesos, siendo capturados o pagando salvaguardas. No hay que olvidar que los gobernadores de las plazas del frente francés tenían dividido el territorio fronterizo bajo su influencia militar como espacio de saqueo y de salvaguarda, generando así una fiscalidad de guerra que no controlaba, a su gran pesar,

\footnotetext{
29 José Javier Ruiz Ibáñez, "Henri IV, la Ligue ou I'Artois" en Le bon historien sait faire parler les silences. Hommages à Thierry Wanegffelen, comp. Fabien Salesse, (Toulouse: Université Toulouse II-Le Mirail- Méridiennes, 2012), pp. 221-234.

${ }^{30}$ Sobre las principales ciudadelas y los problemas para la elección de sus castellanos se cuenta con Joseph Lefèvre, "Les châtelains militaires espagnols des Pays-Bas à l'époque de l'archiduc Albert (1598-1621)", Revue belge de philologie et d'histoire 9/3, (1930), pp. 831-852.

${ }^{31}$ AGR, PEA 1804/1, 15 de febrero de 1592, castillo de Amberes, Mondragón al conde de Mansfeld; ibídem, 1479/3, sin fecha, petición de don Agustín Messía a los Archiduques para mantener el reglamento de 1597 y sus prerrogativas.

32 AGR, PEA 1864/4, sin número, 12 de julio de 1596, Calais, Esteban de Ibarra al cardenalArchiduque.
} 
la administración fiscal ordinaria, y que permitía una capitalización de las ciudades al tiempo que llenaba las bolsas de estos gobernadores. ${ }^{33}$ Esta práctica de extraterritorialidad no era exclusiva de la administración hispana, ni de su posición en Flandes.

\section{3) Disyunción y jerarquía de las carreras}

A diferencia del Cambrésis, en la mayor parte de los casos, la figura del gobernador provincial estaba disociada de la de los gobernadores locales, conservando el primero el título de capitán general, de la provincia de se entiende, ${ }^{34}$ lo que dejaba en una teórica subordinación en cuestiones militares a los segundos. Como se puede observar en Artois esta jerarquía administrativa solía expresar una jerarquía social, reservándose el cargo provincial para miembros de grandes familias y los municipales para segundones, soldados o nobles de menor alcurnia, siguiendo un modelo clásico y rodado. ${ }^{35}$ Pero en ocasiones ser gobernador no quería decir ejercer de facto el poder local. Como los gobiernos implicaban rentas y dignidades los miembros prominentes de la administración real los podían acumular a otros gobiernos o a cargos militares, diplomáticos, o cortesanos de mayor relevancia y beneficio. La naturaleza militar del cargo de gobernador de plaza y/o de castellano de ciudadela significaba que los titulares procedían de las fuerzas armadas en las que seguían desempeñar un papel operativo como capitanes o, mejor aún si se trataba de poblaciones más eminentes, maestros de campo de tercios de infantería española o valona y miembros del Consejo de Guerra ante el gobernador general. ${ }^{36}$ Esto hizo que en la gestión cotidiana del poder en ocasiones no fueran los gobernadores o castellanos nominales quienes lo ejercieran, sino sus tenientes, una figura muy importante que para su actuación no necesitaba de nominación institucional de la corte pero que sumaba de facto muchas de las competencias del titular. Pese a que muchos de ellos no tenían la dignidad social suficiente para ser nombrados en lugar

\footnotetext{
33 José Javier Ruiz Ibáñez, "La guerre, les princes et les paysans. Les pratiques de neutralité et de sauvegarde dans les Pays-Bas et au Nord du royaume de France au XVI et au début du $\mathrm{XVII}^{\mathrm{e}}$ siècle" en Les ressources des faibles. Neutralités, sauvegardes, accommodements en temps de guerre (XVI ${ }^{e}-X V I I I^{e}$ siècle), comp. Jean-François Chanet y Christian Windler (Rennes: Presses Universitaires de Rennes, 2009), pp. 187-204.

${ }^{34}$ Este cargo corresponde al comandante superior de un territorio dado, sumando en su esfera de atribución el mando eminente en dicho territorio, pero estando subordinado a una esfera superior de poder. Así pues es perfectamente lógico que el gobernador provincial fuera capitán general en Artois y que el gobernador general lo fuera en los Países Bajos; por supuesto, esto daba lugar a los conflictos de jurisdicción consustanciales al gobierno en el Antiguo Régimen, pero, en último extremo, sí dividía de forma eficaz la gestión de las fuerzas militares y de las civiles de defensa. Creemos que un estudio global sobre esta figura, la del capitán general, en la Monarquía sería una buena vía para comprender las formas de territorialización política que se fueron superponiendo a la administración jurisdiccional ordinaria.

35 Paul Rosenfeld, "The provincial governors from the minority of Charles $V$ to the Revolt," Anciens pays et assemblées d'Etats, Standen en landen, 17, (1959), pp. 1-115.

36 AGR, PEA 1804/1, sin número, sin fecha, Cristóbal de Mondragón a Farnesio: Mondragón era a la vez " $\mathrm{m}^{\text {re }}$ de camp d'infanterie espaignolle pour Sa Maté de son conseil de guerre capitaine et gouverneur du chasteau de Gandt" en 1577.
} 
de los titulares, pero si dejaba espacio de acción política, social y económica para avanzar la propia carrera, crear clientelas y ejercer un poder que en principio no se les consideraría.

El origen de los oficiales dependía en gran parte del tipo de guarnición. Son conocidas las reservas de los soldados españoles a obedecer a miembros de otra nación, ${ }^{37}$ así que como las principales ciudadelas de los Países Bajos (Amberes, Gante, Cambrai y Dunkerque ${ }^{38}$ ) estaban guarnecidas por tropas ibéricas parecía lógico que no sólo por una cuestión de fiabilidad política, sino de simple eficacia estos puestos quedaran de facto reservados a españoles. Eran gobiernos más tradicionales los que parecían guardarse para la nobleza segunda local, a la que así se permitía reafirmar la relación con el rey que habían mantenido esta nobleza ${ }^{39}$ y que se confirmaría por la concesión de mercedes hispanas, sobre todo hábitos, en la próxima generación, o incluso más allá como sucedería con Charles de Bonnières, barón de Auchy, hijo de Jean que había sido gobernador de Lens y Hénin quien logró ser gentilhombre de boca del rey en $1612 .{ }^{40}$

Eso permite entender la dinámica de las carreras de los gobernadores de plaza como parte del sistema de servicio internacionalizado entre los dominios de la Monarquía. La guerra contra el enemigo hereditario francés y el esfuerzo militar para acabar con la rebelión de Flandes durante el reinado de Felipe II, generaron oportunidades de carrera tanto en favor de una nobleza secunda local que de nobles extranjeros a los dominios del Circulo de Borgoña. La inserción en la clientela de Granvela y de Margarita de Parma, clientela de la cual heredó Alejandro Farnesio, no hace duda. ${ }^{41}$ Gracias a estos apoyos y al compromiso constante con la causa del rey, en particular en la

\footnotetext{
37 Alicia Esteban Estríngana, "Cabos de guerra: satisfacción de la oficialidad y eficacia bélica en el Ejército de Flandes, entre los siglos XVI y XVII," en Oficiales reales los ministros de la Monarquía Católica, siglos XVI-XVII (Valencia: Universitat de València, 2012), pp. 265-293, esp. 274-282.

38 Sobre la magnitud de los presidios respecto al ejército de Flandes se remite al clásico Geoffrey Parker, The army of Flanders and the Spanish Road 1567-1659 (Cambridge: Cambridge University Press, 1972).

39 Violet Soen, "Enviados a la corte para servir al rey. Misiones de nobles flamencos a la Corte española durante la revuelta de los Países Bajos (1565-1576)", en Servir al rey en la Monarquía de los Austrias. Medios, fines y logros del servicio al soberano en los siglos XVI y XVII, comp. Alicia Esteban Estríngana, (Madrid: Sílex, 2012), pp. 447-472.

40 Alicia Esteban Estríngana, "Agregación de territorios e integración de elites. Flandes y la Monarquía de Felipe III (1598-1621)", Studia Historica Historia Moderna 32, (2010), pp. 261304, especialmente 283-304. En términos generales se remite a Luc Duerloo, Dynasty and Piety. Archduke Albert (1598-1621) and Habsburg Political Culture in an Age of Religious Wars (Londres-Burlington: Ashgate, 2012).

${ }_{41}$ Maurice Van Durme, Antoon Perrenot, Bisschop van Atrecht, Kardinaal van Granvelle, Minister van Karel V en van Filips II (1517-1586), (Bruselas: Paleis der Academiën, 1953). Sobre la presencia de italianos en el ejército de los Países Bajos se remite a Giuseppe Bertini, (dir.), Militari italiani dell'esercito di Alessandro Farnese nelle Fiandre, (Salsomaggiore: Mattioli $1885,2013)$; Angeloantonio Spagnoletti, "Quale patriottismo per i soldati napoletani al servizio della Monarchia Cattolica?", en Guerra y Sociedad en la Monarquía Hispánica. Política, Estrategia y Cultura en la Edad Moderna (1500-1700), comp. Enrique García Hernán y Davide Maffi, (Madrid: Ediciones del Laberinto-Fundación Mapfre-CSIC, 2006), pp. 163-179; Gregory Hanlon, Twilight of a Military Tradition: Italian Aristocrats and European Conflicts, 1560-1800 (Londres: UCL Press, 1998).
} 
crisis de los años 1576-1578, pero sólo algunos de los más selectos gobernadores de plaza obtuvieron el cargo de provincias minores. Largilla, gobernador de Landrecies, procedía del Franco-Contado como Granvela. El portugués Gaspar de Robles, gobernador de Philippeville, coronel de infantería valona en 1568 , se relacionaba con la nobleza local por beneficiar del título y del apoyo de su esposa, Jeanne de Saint-Quentin, baronesa de Billy en Artois, que siempre estuvo dispuesta a defender sus intereses ante Alba y Farnesio. ${ }^{42}$ Robles reemplazó el señor de Hierges al gobierno de la provincia de Frisia de 1573 a 1576 y fue de nuevo propuesto en $1582 .{ }^{43}$ Cuando el murió al sitio de Amberes en 1585, su viuda se dirigió directamente al rey con la aprobación de Farnesio para asegurar el futuro de sus hijos. ${ }^{44}$ Juan de Robles obtuvo en 1593 el gobierno provincial de Lille, ejerciéndole hasta su muerte en $1621 . .^{45}$

El recorrido del gobernador de Béthune, don Gastón Spínola, que pertenecía a la rama siciliana de la familia genovesa epónima, sugiere paralelismos con el de Robles. Tenía un anclaje en la nobleza segunda de Artois, casándose en 1586 con Marie de Renty, señora de Bruay en Artois y sobrina de Felipe de Récourt, barón de Licques y entonces gobernador de Lille y Tournai. Llegó a gobernador de la villa de Béthune de 1594 a 1597, de la provincia de Limburgo y Outre-Meuse de 1597 a 1612 y su nieto Felipe Spínola, conde de Bruay, al de Lille de 1655 hasta la conquista francesa de 1667. En 1601, el nombramiento de Gastón Spínola al gobierno de Cambrai, aunque detentado por un español, Sancho de Leyra, suscitó tensiones por ser extranjero, pero fue otro español, Juan de Ribas, quien fue elegido, ilustrando la irrupción de los nuevos hombres y el debate general sobre el derecho al mando. ${ }^{46}$ Pero aunque la mayor parte de los gobernadores, castellanos o capitanes de plazas hubiera ascendido por sus méritos, su carrera tenía un límite ${ }^{47}$ ya que no podían acceder a un cargo provincial: su capital y su visibilidad social resultaban insuficientes para adelantarse a la gran nobleza,

\footnotetext{
42 Raymond Fagel, "La imagen de dos militares españoles decentes en el ejercito del duque de Alba en Flandes: Cristóbal de Mondragón y Gaspar de Robles", en Encuentros de ayer y reencuentros de hoy: Flandes, Países Bajos y el mundo hispánico en los siglos XVI-XVII, comp. Patrick Collard, Miguel Norbert Ubarri y Yolanda Rodríguez Pérez (Gante: Academia Press, 2009), pp. 73-91.

43 AGS, Secretarías provinciales, 2596, 02 de septiembre de 1574, Bruselas: commission du conseil de guerre pour Gaspar de Roblès, $s^{r}$ de Billy.

${ }^{44}$ AGS, E 589, n 62, 9 de abril de 1585, Beveren, la señora de Billy a Felipe II, y $n^{\circ} 107,10$ de abril de 1585, Beveren, Farnesio a Felipe II: "por la muger e hijos de Mos. de Billy".

45 Yves Junot, Le gouverneur et les officiers de la gouvernance de Lille (1516-1667). (Memoria DEA, Universidad de Lille 3, 1994), pp. 29-36.

46 AGS, E 618, n²120, 25 de febrero de 1601, Bruselas, archiduque Alberto a Felipe III; Esteban Estríngana, "Cabos de guerra...".

47 Antonio Jiménez Estrella, "Mérito, calidad y experiencia: criterios volubles en la provisión de cargos militares bajo los Austrias", en Oficiales reales: los ministros de la Monarquía Católica, siglos XVI-XVII (Valencia: Universitat de València, 2012) pp. 241-264; y, del mismo autor, "Los nuevos bellatores de su Majestad. Reflexiones en torno al servicio militar al rey en los siglos XVI y XVII," en Servir al rey en la Monarquía de los Austrias. Medios, fines y logros del servicio al soberano en los siglos XVI y XVII (Madrid: Sílex, 2012), pp. 387-413.
} 
que fuera de los Países Bajos o de otra nación, en la distribución de los favores de los soberanos. ${ }^{48}$

\title{
La naturaleza del poder en tiempos de reconciliación
}

\author{
1) El debate sobre el gobernador "natural" y "extranjero" en las provincias \\ de la Unión de Arras
}

La variable geografía política y administrativa que definían los diversos tipos de gobernadores es elocuente de tres elementos que confluyeron a la hora de reconstruir los consensos políticos en los Países Bajos tras 1580: las tradiciones heredadas del periodo borgoñón, la irrupción con fuerza de un poder soberano con Carlos $\mathrm{V}$ y los medios por el que éste se había restablecido con Parma. En la mayoría de ciudades donde el retorno a la autoridad real se fundó en un pacto y en la consiguiente capitulación, esta última garantizaba el mantenimiento del statu quo previo, lo que solía traducirse en la aceptación por el príncipe de los límites de su capacidad de ejercer la coerción. La república que se había sometido conservaba todas sus competencias, especialmente significativas en defensa y justicia. Así que el gobernador contaba con una limitada o inexistente fuerza militar intramuros. Su nominación partía de los medios tradicionales de designación, contaría con la propuesta del gobernador provincial y pasaría por el sistema polisinodial propio de los Países Bajos. Así, en 1596, a la muerte de Adrien II, señor de Gomiecourt ${ }^{49}$, gobernador de Hesdin y antes de Maastricht, el archiduque Alberto inició un proceso informativo en el que el gobernador de Artois le propuso una terna de la que seleccionó al coronel La Coquele, un conocido líder militar "del país". ${ }^{50}$ Tampoco es casual que tras la conquista de Hulst

\footnotetext{
48 Dries Raeymaekers, One Foot in the Palace. The Habsburg Court of Brussels and the Politics of Access in the Reign of Albert and Isabella, 1598-1621, (Lovaina: Leuven University Press, 2013), pp. 151-160.

${ }^{49}$ Gomiecourt sumaba toda una buena panoplia de mercedes regias: gentilhombre de boca del rey de España, miembro del Consejo de Guerra, diplomático en Alemania y Francia, y teniente general con don Juan de Austria, casado con Philippine de Montmorency, su hijo Philippe, gobernador de Arras y de Artois, seria agraciado con un título de conde por Felipe IV ya en 1633; François-Alexandre Aubert de la Chesnaye Des Bois et Badier, Dictionnaire de la noblesse (París, Antoine Boudet, 1774), VII, p. 274.

$50 \mathrm{La}$ interinidad de este importante gobierno de la frontera en Artois venía incluso de antes de la muerte de Gomiecourt. El gobernador había sido preso en 1595 por matar a "un rufían que havia puesto una casa de mujeres villanas" junto al foso de la villa; el conde de Fuentes ordenó que, como el gobernador de Hesdin era caballero de Santiago (desde 1582), debía ser la Orden quien entendiera el proceso, pero, como no lo comunicó a Madrid, su prisión se prolongó; AGS E 612 no 95, 15 de mayo de 1596, Ardres, J.B. de Tassis a Felipe II. BNF ms lo 528, fo 69, 1 de julio de 1596, Gante, el archiduque Alberto al marqués de Varambon; fo 48, 6 de julio de 1596, Arras, De Noyeu al marqués de Varambon ; AGR, PEA 2780-1, sin número, 1 de septiembre de 1596, patente por Charles de Lalaing, señor de Achicourt como sustituto en el regimiento de La Coquelle; AGR, PEA 205 fo 62, 14 de octubre de 1596, Bruselas, el archiduque Alberto a Felipe II (minuta de despacho); Carlos Coloma, Las guerras de los Estados-Bajos, desde el año de 1588 hasta el de 1599, (Madrid, BAE XXVIII, 1948), 140a. Charles Hirschauer, Les Etats d'Artois de leurs origines à l'occupation française, 1340-
} 
(Zelanda del Sur) ese mismo año, el gobernador general entregara el gobierno al señor de la Biche, que parecía reunir las condiciones necesarias tanto para controlar el territorio, acababa de ocupar la superintendencia de guerra del país de Waes y sabía lo que era vérselas con los vrijbuters ${ }^{51}$, como para intentar restablecer una ciudad. A nadie escapó tampoco que era una forma de proclamar que el gobierno no se apoyaba sólo en los españoles para dominar los Países Bajos.

Significativamente estas plazas, que solían ser mayoría al menos en las provincias que cumplieron la Unión de Arras en 1579, estaban reservadas para los naturales del país. Nombrar a un no natural de los Países Bajos, aunque estuviera claramente aclimatado, resultaba escandaloso y generaba una notable oposición tanto por el contrafuero que suponía como por la pérdida de espacios de promoción para la propia nobleza local. Después de la conclusión de la Unión de las provincias católicas y la firma de la Paz de Arras con Felipe II en 1579, el pacto de reconciliación iniciado por las elites católicas introducía una preferencia a "quelque personnaige naturel des pays de pardeca" en la atribución de los cargos. A fin de respetar los términos de la paz de Arras, Farnesio exigió a Cristóbal de Mondragón que se repartiera del gobierno de la provincia de Limburgo y Outre-Meuse en provecho de un valón en $1580 .{ }^{52}$ Este discurso solía ser utilizado por les Estados provinciales para definir la comunidad política mucho tiempo después de la pacificación. ${ }^{53}$ Gastón Spínola, ya había sufrido por eso como gobernador de Béthune, a pesar de su enraizamiento en Artois. ${ }^{54}$

\section{2) El tiempo de los gobernadores españoles}

Por el contrario, las localidades que el rey había adquirido por la fuerza o por la negociación con las guarniciones que las poseían habían permitido proclamar la instauración de un orden que superaba parte importante de los limites políticos previos y que se fundaba en una capitulación mucho más severa o en la simple conquista, lo que implicaba de facto y de iure la supresión de los privilegios y la restauración de sólo aquellos que la gracia real acordara. Es en este tipo de plazas donde se introducen las mayores

1640, (París-Bruselas, 1923, 2 vol.), II, 94, sobre la asamblea de los Estados de Artois de 3 de julio de 1596 en la que se acuerda pedir al archiduque Alberto que el sustituto de Gomiencourt ("très gravement malade") fuera natural del país. El registro de la recepción de La Coquele en Hesdin se conserva en Archives Départementales du Pas-de-Calais en Arras (en adelante ADPaC) EDEP 447 BB1, 19 de septiembre de 1596.

51 AGS, E 611, n० 126, 29 de agosto de 1596, Amberes, el archiduque Alberto a Felipe II.

52 AGR, PEA 1804/1, 2 de marzo de 1580, Maastricht, Farnesio a Cristóbal de Mondragón: ordonnance de remettre le gouvernement de Lembourg es mains du $S^{r}$ de Ruysbroeck.

53 Véase Tamar Herzog, Defining Nations. Immigrants and Citizens in Early Modern Spain and Spanish America, (New Haven-Londres: Yale University Press, 2003), pp. 1-16.

54 AGS, E 612, n¹16, informe de Ibarra sobre Spínola: "los de la provincia de Artois se han agraviado y reclamado que allí ayan puesto gobernador estranjero pero hasta aora se ha llevado de manera que creo que no harán instancia". 
guarniciones y donde la dominación regia se reviste de una forma más coactiva, aunque sin eliminar en absoluto las competencias defensivas de la burguesía que no sólo iban a ser preservadas, sino que pronto estarían siendo potenciadas por el propio gobierno. Los tipos ideales serían villas como Amberes rendida tras el largo asedio en 1585 o Liere entregada por su guarnición escocesa. Sobre estas plazas confluían dos elementos que aproximaban más la administración soberana a la de la Monarquía en detrimento de la administración ordinaria. General y teóricamente las tropas se remuneraban desde la Pagaduría general del Ejército y el príncipe tenía menos ataduras para designar a los responsables. No es casualidad si es en ellas donde se iban a nombrar gobernadores y castellanos no naturales y de preferencia, pero no sólo, españoles. Era proyectar sobre el territorio propio parte de la lógica de establecimiento de un poder en parte nuevo.

Esta irrupción de los oficiales de dependencia directa del príncipe contaba ya con antecedentes. La matriz del sistema se experimentó desde el reinado de Carlos Quinto. El castigo de la rebelión municipal de Gante se materializó con la edificación de una ciudadela urbana en 1540, según un modelo ampliado a partir de 1567 en apoyo a la política de represión del duque de Alba en Amberes. La organización de la defensa de la frontera contra Francia por la fundación de villas colonias reales (Mariembourg en 1546, Philippeville en 1555) o, fuera de los dominios del Emperador, de la ciudadela de Cambrai en 1543, constituyó otro aspecto de la valorización del papel militar y político de los gobernadores de plaza, pero en general, y por el momento, éstas no iban a ser atribuidas a españoles, pero sí a hombres del rey. ${ }^{55}$ La elección de estos gobernadores era obviamente una elección política que se organizó independientemente de los juegos de cursus honorum de la aristocracia provincial, como un ámbito reservado del poder regio, generando así nuevas formas y lógica de clientela y una visión renovada del territorio.

El establecimiento permanente de un ejército real, pagado en gran parte desde España y liderado por españoles, introdujo como elemento nuevo la ascensión de los peninsulares a cargos de gobierno local, lo que, no es ocioso insistir, ya era habitual en los reinos italianos. Esto ampliaba la posibilidad de promoción social de los servidores españoles del rey, pero también de italianos y flamencos. La trayectoria de varios capitanes españoles muestra el seguimiento de esta lógica. Llegado a Flandes en la década de 1540, casado a una mujer de Luxemburgo, el coronel Cristóbal de Mondragón fue nombrado, cuando se firmó la paz del Cateau-Cambrésis, gobernador de Damvillers, en la frontera, y fue movilizado sin discontinuidad en las operaciones militares en los Países Bajos a partir de la rebelión. Tomó el mando de la ciudadela de Gante en 1575, llevó a cabo la reconquista del

55 Nathalie Dereymaeker, "Hesdin, Philippeville et Charlemont. Villes neuves fortifiées, entre théorie et pratique", Histoire urbaine 45/1, (2016), pp. 17-37; Yves Junot y Marie Kervyn, "Creating a border: the Hispanic Monarchy, its subjects and its neighbours of the Southern Low Countries (1477-1659)," en Barriers and Borders, comp. por B. De Ridder y S. Verreyken (eds.), (Turnhout: Brepols, en prensa). 
ducado de Limburgo en 1578 y desempeñó el cargo de gobernador provincial hasta su renuncia de $1580 .{ }^{56}$ Casi una leyenda en vida, y la suya fue muy larga, ${ }^{57}$ Mondragón llegó, como Julián Romero o Francisco Verdugo, a encarnar el ideal de la promoción social por el servicio de armas y de la nobleza de armas imperial.

Tan pronto la conquista de Amberes, Farnesio se nombró castellano de la ciudadela, excluyendo así un poderoso aristócrata natural, el duque de Aerschot Felipe III de Croÿ, e impuso a Mondragón en primer lugar como su teniente antes de hacer su reemplazo a pesar de las resistencias del magistrado urbano, con el fin de re-establecer dentro de sus muros una guarnición española. Este proceso de asignación de un cargo administrativo, el de castellano, en la figura misma del alter ego del rey como un paso intermedio para poder nombrar a un "extranjero" y que esto se convirtiera en algo normal en la administración real es elocuente de la violencia jurídica y política que tal práctica suponía, sobre todo cuando estaba viva la memoria del Saco de Amberes de 1576 en el que se había confirmado de la forma más brutal la capacidad coactiva de la fortaleza sobre la ciudad del Escalda. Ahora se buscaba formalizar un tipo distinto de gobierno, más cooperativo y menos conflictivo en el que el propio Mondragón habría de tener un papel relevante. ${ }^{58}$

Mondragón murió en sus funciones en Amberes en 1596, sin que su sobrino Gaspar, quien había ejercido como su teniente lograra heredar el cargo oficio; éste fue a parar a un oficial muy experimentado, prestigioso y de brillante futuro: don Agustín Messía, que ocupaba la misma función en Cambrai desde el asedio de $1595 .{ }^{59}$ Juan de Ribas, otro militar español de gran experiencia, gobernó la plaza de La Esclusa recuperada de los holandeses, luego la de

\footnotetext{
56 Ángel Salcedo Ruiz, El coronel Mondragón. Apuntes para su biografía. (Madrid, Marcelino Tabares, 1905); Joseph Lefèvre, "Mondragón (Christoval de)," Biographie Nationale de Belgique 37, (1971), pp. 598-601; Fagel, "La imagen de dos militares españoles decentes...," pp. 73-91; AGS, E 589, n46, 11 de noviembre de 1585, Amberes, Farnesio a Felipe II: memoria de las personas más beneméritas que hallo en el tercio de infantería espanola del coronel Christoval de Mondragón.

57 Entre las filas del ejército se especulaba si el "viejo Mondragon" era o no centenario cuando en 1595 dirigió una campaña para rechazar con éxito la incursión lanzada contra Groenlo por Mauricio de Nassau; Diego de Villalobos y Benavides, Comentarios de las cosas sucedidas en los Países baxos de Flandes desde el año de mil quinientos y noventa y quatro hasta el de mil y quinientos y noventa y ocho, (Madrid: Luis Sánchez, 1612 (1611)), pp. 44-46.

58 AGS, E 589, n77, 11 de noviembre de 1585, Amberes, Farnesio a Felipe II: "assi he tomado otro expediente de declararme por castellano a mí mismo ... y por ser el coronel Mondragon de la edad experiencia suficiencia y confiança que se sabe, y el sujeto mas a propósito para el dicho cargo que aquí ay procurare introducirle en el cargo, de ponerle en mi plaça"; AGS, E 590, $\mathrm{n}^{\circ} 17,28$ de febrero de 1586, Bruselas, Farnesio a Felipe II: "como en el expediente que he tomado en declarar mi castellano y dexar en mi lugar la persona del coronel Cristoval de Mondragon que tiene las partes y prendos que se saben con el dicho coronel he hecho que entren alemanes antes que valones porque no sea guarnicion ya declarada de gente natural del pays... no duermo en lo que toca la negociación de introduzir guarnición de spanoles en el dicho Amberes"; sobre los Croÿ en la pacificación de Farnesio, véase a Violet Soen, Vredehandel. Adellijke en Habsburgse verzoeningspogingen tijdens de Nederlandse Opstand (1564-1581) (Amsterdam: Amsterdam University Press, 2012), pp. 158-160.

59 AGS, E 609, n 251, 27 de octubre de 1595, Cambrai, don Agustín Messía a Felipe II, en manos de Martin de Idiáquez su secretario.
} 
Calais de 1596 hasta 1598 (durante la guerra contra Francia). Su nombramiento fue justificado por el archiduque Alberto presentando un perfil idóneo de lo que tendría que ser un buen gobernador: "El gobierno de la villa de Cales encargue al capitán Juan de Ribas que ha tenido el de la Esclusa y la superintendencia de la gente de guerra en Flandes, soldado de muy buenas partes assi en la milicia como en la policía y gobierno en que es muy necesario poner mucho cuidado porque ha quedado casi despoblado el lugar". ${ }^{60}$ La gestión de Ribas, pese a no poder impedir el motín de parte de su guarnición en 1598, fue aplaudida por el gobierno, que lo premió, cuatro años después vez que fue devuelta la plaza a Francia por la paz de Vervins con el de Cambrai que ocupó hasta su muerte en 1616 cuando le sucedería Carlos Coloma. ${ }^{61}$

Estos gobiernos, junto con el de la ciudadela de Gante, representaban el punto culminante para los oficiales españoles de extracción social mediana o baja que habían ido a hacer carrera a Flandes. Coloma era otra cosa, hijo de los condes de Elda ya representa, junto con Messía, la incorporación de los segundones de las casas aristocráticas hispanas en los cargos de gobierno de Flandes, cierto es, no obstante, que ambos contaban con una sobresaliente experiencia y prestigio militar. Con todo, estas designaciones generaban una importante tensión también entre los altos cargos militares de origen peninsular, como evidencia el malestar que acumuló el veterano maestre de campo don Luis de Velasco, cuando se vio postergado por la elección de sus compañeros de armas a los gobiernos de Calais, Cambrai, Amberes y Gante. ${ }^{62}$ Había otros cargos que resultaban menos. Alonso de Luna y Cárcamo lo fue de Liere donde resistió el asalto holandés de 1595.63

El rey solía prejuzgar la nominación de tales oficiales delante del gobernador general que le representaba en los Países Bajos. ${ }^{64}$ Eso favorecía sin duda la incorporación de no naturales de los Países Bajos que servían en los componentes territoriales de los dominios de Carlos Quinto y de Felipe II. Durante las campañas de Farnesio contra los rebeldes, se asignaron sistemáticamente los puertos flamencos conquistados por asedio entre 1583 y 1587 a capitanes españoles con gran experiencia, como Francisco de Aguilar

\footnotetext{
60 AGS, E 611, n 99, 9 de junio de 1596, Saint-Omer, el archiduque Alberto a Felipe II.

61 Ruiz Ibáñez, Felipe II y Cambrai, pp. 101-130.

62 Esteban Estríngana. "Cabos de guerra...", pp. 287-288.

63 José Javier Ruiz Ibáñez, "Monarquía, guerra e individuo en la década de 1590: El socorro de Lier de 1595." Hispania. Revista Española de Historia LVII/1, 195, (1997), pp. 37-62.

64 AGR, PEA 1221, fo 176v, 19 de octubre de 1573, Madrid, instruction et mémoire à notre treschier et tresamé cousin don Louys de Requesens... au faict de la régence et gouvernement et administration en et par nos pays bas,: "quant aux offices nous entendons aussy retenir à nous la disposition de tous gouvernemens généraulx des país de pardela aussy l'admiralité, comprenant esd gouvernemens celui de Lille Douay et Orchies et de Tournay et Tournésis, pareillement les gouvernemens et capitaineries particulières des citez d'Anvers, d'Arras, Béthune, St-Omer, Hesdinfer, Bapaumes, Cambray, Landrechies, Quesnoy, Avesnes, Bouchain, Charlemont et Philippeville, des châteaux de L'écluse, de Lille et de la ville de Dole et Gray".
} 
en Dunkerque. ${ }^{65}$ Es también caso paradigmático la ocupación de villas y ciudades en el norte del reino de Francia entre 1594 y 1598, de los 11 gobernadores hubo cinco españoles (entre ellos Ribas en Calais), un italiano, dos franceses (asistidos por un gobernador de armas ibérico), un portugués y sólo dos naturales de los Países Bajos (y éstos en plazas muy menores). ${ }^{66}$

Los nombramientos de plazas ocupadas, villas sometidas o de las ciudadelas, al menos de las más importantes, eran dados por el Gobernador General y sus patentes quedaban registradas en los libros de la Secretaria de Estado y Guerra. A fin de cuentas se trataba de espacio de jurisdicción real, lo que quedó aún más claro cuando por la cesión de 1598, las tres grandes ciudadelas de Amberes, Cambrai y Gante guardaron un castellano nombrado por el rey católico quien también pagaba la guarniciones, aunque las villas que protegían-vigilaban pertenecieran al dominio ordinario de los Archiduques. ${ }^{67}$ No hay que olvidar que en el proyecto de cesión ese mismo estatuto de dependencia española lo guardaban también las villas ocupadas en el norte de Francia.

\section{3) ¿Por el rey, por la villa o por sí mismo?}

¿Qué características debía tener un gobernador y cuáles tuvieron? La mayor parte de los gobernadores, castellanos y tenientes 'extranjeros' procedían de un sistema que tenía, con todas las limitaciones propias de una sociedad estamental, bastante de meritocrático. A fin de cuentas, el gobierno era consciente que los puestos que se les asignaban eran muy sensibles en los que eficacia profesional resultaba quizá tan necesaria como la eminencia social.

Sin embargo, a la hora de realizar las funciones civiles sus capacidades podían mermar enormemente. En principio la nobleza segunda 'de los Países' debía contar con experiencia militar, aunque quizá no tan desarrollada como la de los 'extranjeros', pero desde luego en principio sí estaba mejor preparada para comprender la idiosincrasia y las sensibilidades urbanas. La cuestión de la lealtad al rey durante la difícil década de 1570 tuvo escasas consecuencias para los oficiales naturales en el contexto de la reconciliación, sobre todo por la persistencia de una cultura nobiliaria descontenta que si se compartía con la nobleza francesa, ${ }^{68}$ resultaba extraña para los hidalgos

${ }^{65}$ Yves Junot, "Réconciliation et réincorporation dans la monarchie hispanique: I'exemple de Dunkerque au temps d'Alexandre Farnèse", Revue du Nord 98/415, (2016), pp. 246-248.

66 José Javier Ruiz Ibáñez, Laberintos de Hegemonía. La presencia militar de la Monarquía Española en Francia a fines del siglo XVI (Valladolid: Universidad, 2012), pp. 90-94.

67 Lefèvre, "Les châtelains espagnols".

68 La libertad de la nobleza es uno de los temas que más han atraído la atención sobre el segundo orden en las Guerras de Religión en Francia, desde al menos la publicación del clásico de Arlette Jouanna, Le devoir de révolte. La noblesse française et la gestation de l'État moderne 1559-1661 (París: Fayard, 1989); no hay espacio aquí para desarrollar el complejo debate 
españoles. Valentin de Pardieu, señor de la Motte, gobernador de Gravelinas a partir de 1574, dejó el bando de Felipe II en noviembre de 1576, convirtiéndose en mariscal de campo del ejército de los Estados generales, pero se unió a don Juan en abril de 1578 tras la victoria de Gembloux. ${ }^{69}$ No obstante su disidencia, la Motte utilizó con habilidad su postura de descontento para aliarse con la nobleza católica de Artois y elegir la reconciliación con el rey, y actuó como agente de la reconquista de los puertos de Flandes junto a Farnesio en $1583 .{ }^{70}$ Su capital político se construyó y se mantuvo hasta su muerte en 1595 durante el sitio de Doullens gracias al control territorial y a las redes de personas tejidas desde su plaza con sus vecinos franceses, ingleses y flamencos. A pesar de las intenciones del rey, las críticas de Ibarra (que sugirió colocar a un capitán español) retrasaron el nombramiento del sobrino y teniente de la Motte, Philippe de Guernonval. ${ }^{71}$ Este solicitó y terminó por lograr, con el apoyo de los "jesuytes d'Espagne", la gobernación titular de la villa porque aseguraba la continuidad de actuación local al servicio de la Monarquía hispánica: ocupó el puesto hasta $1623 .{ }^{72}$ En general, sin embargo, el espectro donde elegir se mostró suficiente para que entre unos y otros, naturales y extranjeros, se pudiera encontrar a agentes regios que cumplieran de forma decorosas ambas funciones.

Si se analizan los comportamientos de los diversos gobernadores en la práctica no hubo una diferencia efectiva a la hora de consolidar la autoridad real entre las villas gobernadas por naturales y aquellas que lo eran por 'extranjeros'. Las tensiones militares que caracterizaron al final del siglo XVI forzaron a los gobernadores y a las burguesías a prevenirse $y$, en no pocos casos, movilizarse contra ataques sorpresa de franceses y holandeses. El comportamiento de los gobernadores o sus tenientes no se distingue por su origen sino por su eficacia. Españoles (en Liere o Doullens) o naturales (en Saint-Omer o Arras) lograron dirigir a las fuerzas defensivas locales en desesperados intentos de proteger 'sus' plazas y lo hicieron con notable

sobre el segundo orden ante la crisis de las Monarquías posterior a 1560, por lo que remitimos sobre su redefinición cultural a Benjamin Deruelle, De papier, de fer et de sang: chevaliers et chevalerie à l'épreuve de la modernité (ca. 1460-ca. 1620), (París: Publications de la Sorbonne, 2015).

69 J. L. A. Diegerick, ed., Correspondance de Valentin de Pardieu, seigneur de la Motte, gouverneur de Gravelines (1574 - 1594) (Brujas: Vandecasteele-Werbrouck, 1857), pp. 4-61. 70 Violet Soen, "Les Malcontents au sein des États-Généraux aux Pays-Bas (1578-1581): Défense du pouvoir de la noblesse ou défense de l'orthodoxie?", en La noblesse et la défense de I'orthodoxie XIII $I^{\text {ème-XVIII }}{ }^{\text {ème }}$ siècles, comp. Ariane Boltanski y Frank Mercier, (Rennes: Presses Universitaires de Rennes, 2011), pp. 135-149 ; y, de la misma autora, Vredehandel, (2012), pp. 126-133.

71 AGR, PEA 203, fo 230, 9 de junio de 1597, San Lorenzo, Felipe II a Alberto de Austria, y AGS, E 612, n¹16: "El senor de Guernonval ... es criatura de La Motte y tienese buena opinion de, pero no es subjecto tal que se le pueda fiar una plaza de tan grande importancia. Seria bien medio (...) meter en esta plaza un hombre de mas prendas y confiança muy averiguada y pudiendose encaminar que entrasse alli spanol".

72 AGR, PEA 1852-4, sin número, Gravelinas, 23 de septiembre y 7 de octubre de 1595, y 3 de mayo y 3 de septiembre de 1596, el señor de Guernonval al conde de Fuentes, al secretario François Le Vasseur señor de Moriensart, a un ministro y al archiduque Alberto. 
éxito. ${ }^{73} \mathrm{Y}$ en las plazas marítimas, los gobernadores españoles ampliaron las relaciones de interés con las elites locales municipales y mercantiles, participando en el seno de asociaciones empresariales a la privatización de la guerra en el mar. Ribas en Calais, Guernonval (el único valón en cargo en los puertos flamencos) en Gravelinas, Aguilar en Dunkerque fletaron navíos corsarios, y este último fue tomado como prisionero durante un curso en 1597 por los rebeldes de Ostende que le enviaron en Inglaterra. ${ }^{74}$ Podían hacer la guerra por cuenta propia en el espacio violento de oportunidad de recursos en que se había convertido el mar del Norte desde la rebelión de Flandes, a la vez sirviendo al rey y desarrollando buenas relaciones personales de negocios con las burguesías locales y con sus vecinos.

Típico hombre de frontera, Guernonval simultaneaba bien su fidelidad al rey con una continua iniciativa mercantil. Su sostén al mantenimiento del comercio con Calais hasta 1595 sólo fue uno más de los episodios que protagonizó para activar el tráfico; en 1597 apoyó la idea de un burgués de Saint-Omer que volvía de Holanda (Jean Heyndricq battelier de oficio) para permitir que los holandeses comerciaran con Saint-Omer a través del puerto de Gravelinas, eso sí pagando licencias como hacían en La Esclusa respecto a Brujas; de hecho, el gobernador se molestó por lo frío y ambiguo de la respuesta de la villa ${ }^{75}$. En este deseo de activar el tráfico por licencia coincidió con las demandas de los comerciantes de Saint-Omer asfixiados por el cierre mercantil que suponía el bloqueo holandés de Calais desde $1596^{76}$. En 1618 el gobernador volvió a jugar un importante papel en la planificación de la reforma del puerto y mejorar la navegabilidad del Hem con Gravelinas ${ }^{77}$. No se paraban aquí las actividades empresariales del gobernador, quien, como ya se ha visto, también armaba bajeles para ir al corso y exigía unos rescates tan excesivos a sus presas que incluso se vio reprehendido por el archiduque Alberto durante el sitio de Ostende, cuando el sobrino de Felipe II le tuvo que recordar que "nous faisons la guerre pour chastier les rebelles, et non pour gaigner de l'argent". ${ }^{78}$

\footnotetext{
73 Ruíz Ibáñez, "Monarquía, Guerra y individuo"; Adolphe Guesnon, La surprise d'Arras tentée par Henri IV en mars 1597 et le tableau de Hans Conincxloo (Arras: Ségaud, 1907).

74 Patrick Villiers, Les corsaires du littoral. Dunkerque, Calais, Boulogne, de Philippe II à Louis XIV (1568-1713) (Villeneuve d'Ascq: Presses universitaires du Septentrion, 2000), pp. 128130 (el que menciona a "Jean de Rynes" por Juan de Ribas); Jean-Philippe Priotti, "Aguilar", Dictionnaire des corsaires et pirates, G. Buti y P. Hrodej (dir.), (París: CNRS Editions, 2013), pp. 4-5; Junot, "Réconciliation et réincoporation", pp. 249-254.

75 Archives Municipales de Saint-Omer (en adelante AMStO) CM 24, no 70, 3 de octubre de 1597, Gravelinas, el señor de Guernonval a la villa de Saint Omer; no 71, 8 de octubre, minuta de respuesta, y no 98, 15 de octubre de 1597, nueva carta de Guernonval.

76 Como se puede ver por la petición de los "doyens, compaignons et anchiens du mestiers des batteliers" a la villa de Saint-Omer. El ejemplo del acuerdo de comercio bajo licencia estaba en poder del ayuntamiento de Saint-Omer como muestra AMStO CM 23, no 227, 1597 documentación sobre el comercio entre Zelanda y Brujas.

77 Todos los papeles en ADN (Archives départementales du Nord, Lille) B 18757; sobre el tráfico a través de dicho río (y los canales de alrededor) y los derechos de la villa de Saint Omer, v. Justin de Pas, "La ville de Saint-Omer et le port de Gravelines," Mémoires de la Société des Antiquaires de la Morinie 35, (1931).

78 Henri Malo, Les corsaires Dunkerquois et Jean Bart, (París: Mercure de France, 1912-1913, II vols), 1912, I, p. 250.
} 
Seguramente el teniente de gobernador de Gravelinas no veía contradicción alguna en sumar beneficio personal y servicio regio ello, y en el fondo, en esto debía de coincidir con los otros gobernadores, baste recordar que la intervención contra las cuentas de los gobernadores de frontera en la guerra contra Francia realizada por la Chambre des Comptes de Lille se basaba en una contradicción, por un lado se pide al gobernador beneficios. ${ }^{79}$

Esto permite aventurar una reflexión sobre la formación común de dichos gobernadores. Si es así, y así lo parece, en realidad se trataría de una elite de administradores especializados en el servicio regio a través de carreras militares que generaban experiencias parecidas, una cultura política compartida y una formación técnica similar. Lo importante no era por lo tanto, el origen de tal o cual gobernador, sino su nivel de excelencia logrado en el servicio regio, su conocimiento y su capacidad de inserción en el medio político flamenco y de sus siempre complejas sensibilidades locales.

Los recelos de Ibarra se mostraron pues injustificados, pero no sólo en lo que se refiere a la fiabilidad militar, sino también al efecto político de elegir a gentes de un sitio u otro. No hubo, en la práctica, una diferencia mayor en cuanto a la lealtad al régimen Habsburgo entre las que eran gobernadas por gentes del país o 'tiranizadas' por capitanes españoles. En casi todas ellas los procesos de consolidación política de las burguesías contrarreformadas se completó de forma eficaz y a ello ayudo, y no poco, la existencia de mediadores que actuaban entre esa burguesía y el poder imperial. Claro, como hubo múltiples de estos agentes que compartían espacio con los gobernadores (los obispos, los jesuitas...), queda por dilucidar qué efecto tuvo el origen de los gobernadores a la hora de permitir movilidades sociales hacia la elite, acelerar la negociación bianual o trianual de las aides y los donativos o simplemente reforzar la identidad urbana. La elite imperial internacional que estaba surgiendo en estas posiciones mediadas daba una imagen de Monarquía global que buscaba consolidar un proyecto político, el de unos Estados Bajos católicos, del que eran protagonistas en primer lugar las burguesías locales.

Para sostener tenían que pactar con el poder regio y el gobierno colocó a los agentes adecuados para hacerlo. El capitán mexicano Diego de Villalobos en su relato del socorro de Liere no deja de notar el mérito que en la movilización de los burgueses de Amberes tuvo el Gerónimo Walter Zapata pagador general del ejército. No era un comentario inocuo: Walter Zapata, que debía de estar negociando asientos en la ciudad, formaba parte de una familia de origen a la vez castellano y alemán de Colonia... y era cuñado y protector de Villalobos. ${ }^{80}$ Los burgueses de Amberes también contaron con la

79 Sobre la gestión de la villa de La Capelle: José Javier Ruiz Ibáñez, "Rêves impériaux et cauchemars locaux: la Thiérache et la politique espagnole à la fin du XVIème siècle", Mémoires de la Fédération des Sociétés d'Histoire et d'Archéologie de l'Aisne, LVI, (2011), pp. 7-24.

80 Dennis Grê Ponce, La Moral y la Guerra. Los cronistas de Flandes: expresión de la cultura política de la Monarquía Hispánica (siglos XVI y XVII) (tesis doctoral, Universidad de Murcia, 
ayuda del español Gaspar de Mondragón quien también trató de hacerse atribuir el mérito, ${ }^{81} \mathrm{y}$, por supuesto Alonso de Luna lo reclamó para sí. ${ }^{82}$ Cada narrativa pone el acento en el protagonismo de uno u otro a la hora de organizar el socorro: para Villalobos su cuñado, para Mondragón él mismo y para los burgueses de Amberes sus líderes más implicados. En realidad su brillante victoria sobre los holandeses mostraba no sólo la existencia de instituciones renovadas, sino su capacidad de coordinarse entre ellas más allá del origen o la posición de cada cual. Los gobernadores no eran los únicos protagonistas de la construcción y la consolidación de la nueva sociedad política, pero desde luego, sí jugaron un papel decisivo en ella.

\section{Conclusiones}

La administración regia había logrado crear un mecanismo complejo de gestión política que le permitía aunar las relaciones, jurisdicciones y dependencias tradicionales con los medios que aportaba la inserción de un imperio politerritorial. Ciertamente no había habido un plan maestro, sino múltiples discursos concurrentes y en una práctica un tanto caótica. Los deseos de Ibarra de reducir las plazas de gobierno a españoles resultaron tan frustrados como las aspiraciones de la nobleza local por monopolizarlas. En el fondo la práctica había mostrado que ambos eran eficaces para consolidar una dominación que movilizara apoyo social y garantizara la lealtad al lejano rey. Al final los gobernadores españoles supieron adaptarse al mudo político local y los naturales no flaquearon en su fidelidad al rey y en su eficacia militar. Cierto, hay entre los gobernadores una tendencia a una territorialización de facto: grosso modo españoles en las fronteras terrestres y marítimas (donde más tropas había) y los naturales en el interior, pero hay demasiadas excepciones para que sea una regla general; y quizá lo más importante sea el tipo de administrador y sus prácticas más que sus orígenes. Por supuesto, estamos lejos de una administración burocrática y de un cursus honorum estable, pero entre estos clientes directos del rey sí comenzaba a crearse una cultura política y administrativa de servicio y de gobierno directo de un soberano ausente; una vía a la promoción que se adaptaba a las realidades de patronazgo y clientela y a la capacidad de representación de cada territorio pero que primaba la capacidad de integración y de comprensión de las otras culturas políticas, comenzando por la urbana, que

2015); José Javier Ruiz Ibáñez y Gabriela Vallejo Cervantes, "Viviendo 'sin dexar parte donde las Cruzes españolas no hayan sido conocidas'. Don Diego de Villalobos y Benavides en la administración imperial de la Monarquía hispánica." Historia Mexicana 243-3 LVI, (2012), pp. 1109-1170.

81 AGR, PEA 1836-1, 14 de octubre de 1595, del castillo de Amberes, Du Chastellet al marqués de Havré; AGS, E 1645, n 1616, 'Relacion de quatro consultas de Estado": "Gaspar de Mondragon ha servido mucho tiempo y ultimate siendo ten ${ }^{\text {te }}$ del Cato de Ambers socorrio la Villa de Liera y se perdiera sino fura por el por lo qual y ser sobrino del coronel Mondragon se empleara con el muy bien alguna renta".

82 AGR, PEA 1836-1, 17 de octubre de 1595, don Alonso de Luna y Cárcamo al marqués de Havré. 
en principio les era ajena. Unos y otros construyeron una Monarquía que estaba en proceso de integrarse sin perder sus singularidades. 
Bibliografía:

Bertini 2013: Giuseppe Bertini (dir.), Militari italiani dell'esercito di Alessandro Farnese nelle Fiandre, (Salsomaggiore: Mattioli 1885, 2013).

Bourquin 1995: Laurent Bourquin, Noblesse seconde et pouvoir en Champagne, aux XVI et XVII siècles, (París: Publications de la Sorbonne, 1995).

Bourquin 2001: Laurent Bourquin, Les nobles, la ville et le roi: l'autorité nobiliaire en Anjou pendant les guerres de religion (1560-1598), (París: Belin, 2001).

Carroll 1998: Stuart Carroll, Noble Power during the French Wars of Religion. The Guise Affinity and the Catholic Cause in Normandy, (Cambridge: Cambridge University Press, 1998).

Carroll 2006: Stuart Carroll, Blood and Violence in Early Modern France, (Oxford: Oxford University Press, 2006).

Centenero 2012: Domingo Centenero de Arce, "¿Una monarquía de lazos débiles? Circulación y experiencia como formas de construcción de la Monarquía Católica" en Oficiales reales los ministros de la Monarquía Católica, siglos XVI-XVII, comp. Juan Francisco Pardo Molero y Manuel Lomas Cortés, (Valencia: Universitat de València, 2012), pp. 9-22.

Coloma 1948: Carlos.Coloma, Las guerras de los Estados-Bajos, desde el año de 1588 hasta el de 1599, (Madrid, BAE XXVIII, 1948).

Constant 1989: Jean-Marie Constant, "Un groupe socio-politique stratégique dans la France de la première moitié du XVII ${ }^{\mathrm{e}}$ siècle: la noblesse seconde", en L'État et les aristocraties (France, Angleterre, Écosse), XII ${ }^{e}-X V I I^{e}$ siècle, comp. Philippe Contamine, (París: Rue d'Ulm, 1989), pp. 279-304.

De Ridder 2016: Bram De Ridder, Lawful Limits. Border Management and the Formation of the Habsburg-Dutch Boundary, ca. 1590-1665, (Tesis doctoral, KU Leuven Lovaina, 2016).

Denys y Paresys 2007: Catherine Denys y Isabelle Paresys, Les anciens PaysBas à l'époque moderne (1404-1815). Belgique, France du Nord Pays-Bas, (París: Ellipses, 2007).

Dereymaeker 2016: Nathalie Dereymaeker, "Hesdin, Philippeville et Charlemont. Villes neuves fortifiées, entre théorie et pratique", Histoire urbaine 45/1, (2016), pp. 17-37. 
Deruelle 2015: Benjamin Deruelle, De papier, de fer et de sang: chevaliers et chevalerie à l'épreuve de la modernité (ca. 1460-ca. 1620), (París: Publications de la Sorbonne, 2015).

De Schepper 1990: Hugo De Schepper, "Centralismo y autonomismo en los Países Bajos durante el siglo XVI," en Centralismo y autonomismo en los siglos XVI-XVII: homenaje al profesor Jesús Lalinde Abadía, comp. Aquilino Iglesia Ferreirós y Sixto Sánchez-Lauro Pérez (Universitat de Barcelona, 1990), pp. 487-516.

De Schepper 1996: Hugo De Schepper, "El funcionariado y la burocratización en el gobierno y en las provincias de Flandes Regio, siglos XVI y XVII," en Chronica nova: Revista de historia moderna de la Universidad de Granada 23, (1996), pp. 403-436.

De Schepper 1998: Hugo De Schepper, "Pena o gracia en Flandes bajo Carlos V y Felipe II (1521-1598)", en Felipe II (1527-1598): Europa y la monarquía católica, comp. José Martínez Millán, (Madrid: Parteluz, 1998).

De Schepper 2008: Hugo De Schepper, "Justicia, gracia y policía en Flandes bajo el Duque de Alba (1567-1573)", en V Centenario del Nacimiento del III Duque de Alba, Fernando Alvarez de Toledo. Actas: Piedrahíta, El Barco de Ávila y Alba de Tormes (22 a 26 de octubre de 2007), (Ávila, Diputación de Ávila, Institución Gran Duque de Alba: Diputación de Salamanca, 2008).

Diegerick 1857: J.L.A. Diegerick (ed.), Correspondance de Valentin de Pardieu, seigneur de la Motte, gouverneur de Gravelines (1574 - 1594), (Brujas: Vandecasteele-Werbrouck, 1857).

Duerloo 2012: Luc Duerloo, Dynasty and Piety. Archduke Albert (1598-1621) and Habsburg Political Culture in an Age of Religious Wars, (LondresBurlington: Ashgate, 2012).

Durme 1953: Maurice Van Durme, Antoon Perrenot, Bisschop van Atrecht, Kardinaal van Granvelle, Minister van Karel V en van Filips II (1517-1586), (Bruselas, Paleis der Academiën, 1953).

Esteban 2010: Alicia Esteban Estríngana, "Agregación de territorios e integración de elites. Flandes y la Monarquía de Felipe III (1598-1621)", Studia Historica Historia Moderna 32, (2010), pp. 261-304.

Esteban Estríngana 2012: Alicia Esteban Estríngana, "Cabos de guerra: satisfacción de la oficialidad y eficacia bélica en el Ejército de Flandes, entre los siglos XVI y XVII," en Oficiales reales los ministros de la Monarquía Católica, siglos XVI-XVII, comp. Juan Francisco Pardo Molero y Manuel Lomas Cortés, (Valencia: Universitat de València, 2012), pp. 265-293. 
Esteban Estríngana 2012: Alicia Esteban Estríngana, "El servicio: paradigma de relación política en los siglos XVI y XVII," en Servir al rey en la Monarquía de los Austrias. Medios, fines y logros del servicio al soberano en los siglos XVI y XVII, comp. Alicia Esteban Estríngana, (Madrid, Sílex: 2012) pp. 1145.

Fagel 2009: Raymond Fagel, "La imagen de dos militares españoles decentes en el ejercito del duque de Alba en Flandes: Cristóbal de Mondragón y Gaspar de Robles", en Encuentros de ayer y reencuentros de hoy: Flandes, Países Bajos y el mundo hispánico en los siglos XVI-XVII, comp. Patrick Collard, Miguel Norbert Ubarri y Yolanda Rodríguez Pérez, (Gante: Academia Press, 2009), pp. 73-91.

Gantelet 2012: Martial Gantelet, L'absolutisme au miroir de la guerre. Le roi et Metz (1552-1661), (Rennes: Presses Universitaires de Rennes, 2012), pp. 67-109.

Gaudin 2013: Guillaume Gaudin, Penser et gouverner le Nouveau Monde au XVII siècle. L'empire de papier de Juan Díez de la Calle, commis du Conseil des Inde,s (París: L'Harmattan, 2013).

Gil Pujol 2016: Xavier Gil Pujol, La fábrica de la Monarquia. Traza y conservación de la Monarquía de España de los Reyes católicos y de los Austrias, (Madrid: Real Academia de la Historia, 2016).

Grê Ponce 2015: Dennis Grê Ponce, La Moral y la Guerra. Los cronistas de Flandes: expresión de la cultura política de la Monarquía Hispánica (siglos XVI y XVII), (tesis doctoral, Universidad de Murcia, 2015).

Guesnon 1907: Adolphe Guesnon, La surprise d'Arras tentée par Henri IV en mars 1597 et le tableau de Hans Conincxloo, (Arras: Ségaud, 1907).

Hanlon 1998: Gregory Hanlon, Twilight of a Military Tradition: Italian Aristocrats and European Conflicts, 1560-1800, (Londres: UCL Press, 1998).

Herrero y Ruiz 2009: Manuel Herrero Sánchez y José Javier Ruiz Ibáñez, "Defender la patria y defender la religión: las milicias urbanas en los Países Bajos españoles, 1580-1700", en Las milicias del rey de España. Sociedad, política e identidad en las Monarquías Ibéricas, comp. José Javier Ruíz Ibáñez, (Madrid: Fondo de Cultura Económica, 2009), pp. 268-296.

Herzog 2003: Tamar Herzog, Defining Nations. Immigrants and Citizens in Early Modern Spain and Spanish America, (New Haven-Londres: Yale University Press, 2003). 
Hirschauer 1923: Charles Hirschauer, Les Etats d'Artois de leurs origines à I'occupation française, 1340-1640, (París-Bruselas, 1923, 2 vol.).

Hortal Muñoz 2004: José Eloy Hortal Muñoz, El manejo de los asuntos de Flandes, 1585-1598, (tesis doctoral, UAM, 2004).

Janssen 2014: Geert H. Janssen, The Dutch Revolt and Catholic Exile in Reformation Europe, (Cambridge: Cambridge University Press, 2014).

Jiménez 2012: Antonio Jiménez Estrella, "Mérito, calidad y experiencia: criterios volubles en la provisión de cargos militares bajo los Austrias", en Oficiales reales: Ios ministros de la Monarquía Católica, siglos XVI-XVII, comp. Juan Francisco Pardo Molero y Manuel Lomas Cortés, (Valencia: Universitat de València, 2012) pp. 241-264.

Jiménez 2012: Antonio Jiménez Estrella, "Los nuevos bellatores de su Majestad. Reflexiones en torno al servicio militar al rey en los siglos XVI y XVII," en Servir al rey en la Monarquía de los Austrias. Medios, fines y logros del servicio al soberano en los siglos XVI y XVII, comp. Alicia Esteban Estringana, (Madrid: Sílex, 2012), pp. 387-413.

Jouanna 1989: Arlette Jouanna, Le devoir de révolte. La noblesse française et la gestation de l'État moderne 1559-1661, (París: Fayard, 1989).

Junot 1994: Yves Junot, Le gouverneur et les officiers de la gouvernance de Lille (1516-1667), (Memoria DEA, Universidad de Lille 3, 1994).

Junot 2012: Yves Junot, "Pratiques et limites de la réconciliation après les guerres de religion dans les villes des Pays-Bas méridionaux (années 1570années 1590)", Revue du Nord, 395-2, (2012), pp. 327-346.

Junot 2015: Yves Junot, "Les milices bourgeoises au temps des guerres civiles: ¿force de déstabilisation ou instrument de pacification de la société urbaine? (Valenciennes, anciens Pays-Bas espagnols, 1560-1600)," en Les milices dans la première modernité, comp. Serge Brunet y José Javier Ruiz Ibáñez, (Rennes: Presses Universitaires de Rennes, 2015), pp. 31-42.

Junot 2016: Yves Junot, "Réconciliation et réincorporation dans la monarchie hispanique: I'exemple de Dunkerque au temps d'Alexandre Farnèse", Revue du Nord 98/415, (2016), pp. 233-256.

Junot y Kervyn 2018: Yves Junot y Marie Kervyn, "Creating a border: the Hispanic Monarchy, its subjects and its neighbours of the Southern Low Countries (1477-1659)," en Barriers and Borders, comp. por B. De Ridder y S. Verreyken (eds.), (Turnhout: Brepols, en prensa). 
Koenigsberger 2001: Helmut G. Koenigsberger, Monarchies, States Generals and Parliaments. The Netherlands in the fifteenth and sixteenth centuries, (Cambridge: Cambridge University Press, 2001).

Le Roux 2000: Nicolas Le Roux, La faveur du roi: mignons et courtisans au temps des derniers Valois, (Seyssel: Champ Vallon, 2000).

Lecuppre-Desjardin 2016: Élodie Lecuppre-Desjardin, Le royaume inachevé des ducs de Bourgogne XIVe-XVe siècles, (París: Belin, 2016).

Lefèvre 1930: Joseph Lefèvre, "Les châtelains militaires espagnols des PaysBas à l'époque de l'archiduc Albert (1598-1621)", Revue belge de philologie et d'histoire 9/3, (1930), pp. 831-852.

Lefèvre 1971: Joseph Lefèvre, "Mondragón (Christoval de)," Biographie Nationale de Belgique 37, (1971), pp. 598-601.

Lottin y Guignet 2006: Alain Lottin y Philippe Guignet, Histoire des Provinces françaises du Nord. De Charles Quint à la Révolution française (1500-1789), (Arras: Presses Universitaires, 2006).

Malo 1912: Henri Malo, Les corsaires Dunkerquois et Jean Bart, (París: Mercure de France, 1912-1913, II vols).

Pardo y Lomas 2012: Juan Francisco Pardo Molero y Manuel Lomas Cortés, Oficiales reales los ministros de la Monarquía Católica, siglos XVI-XVII, (Valencia: Universitat de València, 2012).

Parker 1972: Geoffrey Parker, The army of Flanders and the Spanish Road 1567-1659, (Cambridge: Cambridge University Press, 1972).

Pas 1931: Justin de Pas, "La ville de Saint-Omer et le port de Gravelines," Mémoires de la Société des Antiquaires de la Morinie, 35, (1931).

Pollmann 2011: Judith Pollmann, Catholic Identity and the Revolt of the Netherlands, 1520-1635, (Oxford-New York: University Press, 2011).

Potter 1993: David Potter, War and Government in the French Provinces: Picardy, 1470-1560, (Cambridge: University Press, 1993).

Potter 2001: David Potter, Un homme de guerre au temps de la Renaissance. La vie et les lettres d'Oudart du Biez, maréchal de France, gouverneur de Boulogne et de Picardie (vers 1475-1553), (Arras: Artois Presses Université, 2001). 
Raeymaekers 2013: Dries Raeymaekers, One Foot in the Palace. The Habsburg Court of Brussels and the Politics of Access in the Reign of Albert and Isabella, 1598-1621, (Lovaina: Leuven University Press, 2013).

Rosenfeld 1959: Paul Rosenfeld, "The provincial governors from the minority of Charles $\mathrm{V}$ to the Revolt," Anciens pays et assemblées d'Etats, Standen en landen, 17, (1959), pp. 1-115.

Ruiz 1995: José Javier Ruiz Ibáñez, Las dos caras de Jano. Monarquía, ciudad e individuo. Murcia, 1588-1648, (Murcia: Universidad de Murcia, 1995).

Ruiz 1997: José Javier Ruiz Ibáñez, "Monarquía, guerra e individuo en la década de 1590: El socorro de Lier de 1595." Hispania. Revista Española de Historia LVII/1, 195, (1997), pp. 37-62.

Ruiz 2003: José Javier Ruiz Ibáñez, Felipe II y Cambrai: el consenso del pueblo. La soberanía entre la práctica y la teoría política. Cambrai (15951677), (Rosario: Prohistoria, 2003).

Ruiz 2009: José Javier Ruiz Ibáñez, "La guerre, les princes et les paysans. Les pratiques de neutralité et de sauvegarde dans les Pays-Bas et au Nord du royaume de France au XVI ${ }^{\mathrm{e}}$ et au début du XVII ${ }^{\mathrm{e}}$ siècle" en Les ressources des faibles. Neutralités, sauvegardes, accommodements en temps de guerre $\left(X V I^{e}-X V I I I^{e}\right.$ siècle), comp. Jean-François Chanet y Christian Windler, (Rennes: Presses Universitaires de Rennes, 2009), pp. 187-204.

Ruiz Ibáñez 2011: José Javier Ruiz Ibáñez, "Rêves impériaux et cauchemars locaux: la Thiérache et la politique espagnole à la fin du XVIème siècle", Mémoires de la Fédération des Sociétés d'Histoire et d'Archéologie de l'Aisne, LVI, (2011), pp. 7-24.

Ruiz Ibáñez 2012: José Javier Ruiz Ibáñez, "Henri IV, la Ligue ou I'Artois" en Le bon historien sait faire parler les silences. Hommages à Thierry Wanegffelen, comp. Fabien Salesse, (Toulouse: Université Toulouse II-Le Mirail- Méridiennes, 2012), pp. 221-234.

Ruiz Ibáñez 2012: José Javier Ruiz Ibáñez, "La integración de los Países Bajos en la Monarquía Hispánica," en Las Indias Occidentales. Procesos de incorporación territorial a las Monarquías Ibéricas, comp. Óscar Mazín Gómez y José Javier Ruiz Ibáñez, (México: El Colegio de México, 2012), pp. 109-152.

Ruiz Ibáñez 2012: José Javier Ruiz Ibáñez, Laberintos de Hegemonía. La presencia militar de la Monarquía Española en Francia a fines del siglo XVI, (Valladolid: Universidad, 2012). 
Ruiz Ibáñez 2015: José Javier Ruiz Ibáñez, "Se mobiliser pour le roi à la fin du XVI ${ }^{\mathrm{e}}$ siècle dans les villes des Pays-Bas catholiques", en Les milices dans la première modernité, comp. Serge Brunet y José Javier Ruiz Ibáñez, (Rennes: Presses Universitaires de Rennes, 2015), pp. 155-167.

Ruiz Ibáñez y Vallejo Cervantes 2012: José Javier Ruiz Ibáñez y Gabriela Vallejo Cervantes, "Viviendo 'sin dexar parte donde las Cruzes españolas no hayan sido conocidas'. Don Diego de Villalobos y Benavides en la administración imperial de la Monarquía hispánica." Historia Mexicana 243-3 LVI, (2012), pp. 1109-1170.

Sabatini 2000: Gaetano Sabatini, "Le sentinelle della corona. Capitani spagnoli ai confini settentrionali del regno di Napoli nel Cinquecento," en La Espada y la pluma: il mondo militare nella Lombardia spagnola cinquecentesca, comp. Mario Rizzo, (Lucca: Baroni, 2000), pp. 55-84.

Salcedo Ruiz 1905: Ángel Salcedo Ruiz, El coronel Mondragón. Apuntes para su biografía, (Madrid, Marcelino Tabares, 1905).

Sandberg 2010: Brian Sandberg, Warrior Pursuits: Noble Culture and Civil Conflict in Early Modern France, (Baltimore: The Johns Hopkins University Press, 2010).

Soen 2011: Violet Soen, "Les Malcontents au sein des États-Généraux aux Pays-Bas (1578-1581): Défense du pouvoir de la noblesse ou défense de I'orthodoxie?", en La noblesse et la défense de l'orthodoxie XIII'̀me-XVIII ème siècles, comp. Ariane Boltanski y Frank Mercier, (Rennes: Presses Universitaires de Rennes, 2011), pp. 135-149.

Soen 2012: Violet Soen, "Enviados a la corte para servir al rey. Misiones de nobles flamencos a la Corte española durante la revuelta de los Países Bajos (1565-1576)", en Servir al rey en la Monarquía de los Austrias. Medios, fines y logros del servicio al soberano en los siglos XVI y XVII, comp. Alicia Esteban Estringana, (Madrid: Sílex, 2012), pp. 447-472.

Soen 2012: Violet Soen, "Reconquista and Reconciliation in the Dutch Revolt. The campaign of Governor-General Alexander Farnese in the Dutch Revolt (1578-1592)", Journal of Early Modern History 16, (2012), pp. 1-22.

Soen 2012: Violet Soen, Vredehandel. Adellijke en Habsburgse verzoeningspogingen tijdens de Nederlandse Opstand (1564-1581), (Amsterdam: Amsterdam University Press, 2012).

Spagnoletti 2006: Angeloantonio Spagnoletti, "Quale patriottismo per i soldati napoletani al servizio della Monarchia Cattolica?", en Guerra y Sociedad en la Monarquía Hispánica. Política, Estrategia y Cultura en la Edad 
Moderna (1500-1700), comp. Enrique García Hernán y Davide Maffi, (Madrid: Ediciones del Laberinto-Fundación Mapfre-CSIC, 2006), pp. 163-179.

Villiers 2000: Patrick Villiers, Les corsaires du littoral. Dunkerque, Calais, Boulogne, de Philippe II à Louis XIV (1568-1713), (Villeneuve d'Ascq: Presses universitaires du Septentrion, 2000).

Wanegffelen 2002: Thierry Wanegffelen, "Entre concorde et intolérance; Alexandre Farnèse et la pacification des Pays-Bas," en De Michel de I'Hospital à l'édit de Nantes. Politique et religion face aux Églises, comp. Thierry Wanegffelen, (Aubenas d'Ardèche: Presses Universitaires Blaise Pascal, 2002), pp. 51-70. 